\title{
Midterm survival after thoracic endovascular aortic repair in more than 10,000 Medicare patients
}

\author{
Justin M. Schaffer, MD, Bharathi Lingala, PhD, D. Craig Miller, MD, Y. Joseph Woo, MD, \\ R. Scott Mitchell, MD, and Michael D. Dake, MD
}

Objective: Aneurysms and dissections of the descending thoracic aorta represent a complex substrate with a variety of therapeutic options. The introduction of thoracic endovascular aortic repair (TEVAR) has revolutionized the treatment of thoracic aortic disease. However, longitudinal analyses of post-TEVAR outcomes appropriately stratified by aortic disease remain limited.

\begin{abstract}
Methods: A total of 11,996 patients undergoing TEVAR from 2005-2010 were identified from the Medicare/ Centers for Medicare and Medicaid Services database. Patients were stratified by underlying aortic disease and the presence of Current Procedural Terminology (CPT) codes. Survival was assessed using Kaplan-Meier analysis. Cox proportional hazards analysis determined predictors of survival from TEVAR.

Results: After TEVAR, patients had a median survival of 57.6 months (95\% confidence interval, 54.9-61.3 months). Although patients without CPT codes had significantly fewer recorded comorbidities, TEVAR survival was comparable between patients with and without CPT codes (56.3 vs 59.5 months, $P=.54$ ). The early and late incidence of death varied significantly by aortic disease. Patients with aortic rupture, acute aortic dissection, and aortic trauma had the highest early incidence of death, whereas late survival was highest in patients with acute aortic dissection, aortic trauma, and isolated thoracic aortic aneurysm. Although hospital TEVAR volume was not associated with survival, an independent hospital effect (determined by using a mixed-effect Cox model) associated certain hospitals with a hazard for death $50 \%$ of what it was at other hospitals.
\end{abstract}

Conclusions: TEVAR has been applied to a multitude of aortic diseases in the Medicare population; early and late post-TEVAR survival varies by aortic disease. The late incidence of death remains high in TEVAR recipients, although certain aortic diagnoses such as acute aortic dissection, aortic trauma, and isolated thoracic aortic aneurysm were associated with improved late survival. An independent hospital effect, but not hospital volume, is correlated with post-TEVAR survival. Future analyses of TEVAR outcomes using the Medicare database should adjust for underlying aortic diagnoses and the presence of CPT codes. (J Thorac Cardiovasc Surg 2015;149:808-23)

See related commentary on pages 823-4.

Since its introduction in 1992, thoracic endovascular aortic repair (TEVAR) has seen rapid adoption as a treatment modality for disease involving the descending thoracic aorta. ${ }^{1-3}$

From the Department of Cardiothoracic Surgery, Stanford Hospital and Clinics, Stanford, Calif.

Disclosures: R. Scott Mitchell reports consulting fees from W.L. Gore. Michael D. Dake reports consulting fees from W.L. Gore, Abbott Vascular, and MEdtronic; consulting and lecture fees from Cook Medical; and equity ownership in TriVascular. D. Craig Miller reports consulting fees for Medtronic as well as work with the following companies in the noted capacity: Abbott Vascular Structural Heart (MitraClip), GenTAC Scientific Advisory Oversight Board NHLBI contract to RTI, PARTNER Executive Committee Percutaneous AVR Edwards Lifesciences (nonremunerative, travel expenses only), and the PARTNER trial PI (consulting fees). All other authors have nothing to disclose with regard to commercial support.

Read at the 40th Annual Meeting of The Western Thoracic Surgical Association, Dana Point, California, June 25-28, 2014.

Received for publication June 26, 2014; revisions received Sept 10, 2014; accepted for publication Oct 4, 2014; available ahead of print Dec 23, 2014.

Address for reprints: Michael D. Dake, MD, Stanford Hospital and Clinics, 300 Pasteur Dr, CVRB MC 5407, Stanford, CA 94305 (E-mail: mddake@ stanford.edu). 0022-5223/\$36.00

Copyright (c) 2015 by The American Association for Thoracic Surgery

http://dx.doi.org/10.1016/j.jtcvs.2014.10.036
Initial enthusiasm for TEVAR, spawned by its low procedural morbidity, has been tempered by sobering midterm outcomes, particularly in older patients with multiple comorbidities. ${ }^{4,5}$ Initially approved by the US Food and Drug Administration (FDA) only for the treatment of descending thoracic aortic aneurysms, TEVAR devices were often used off-label to treat catastrophes of the descending thoracic aorta—such as acute, complicated, type B aortic dissections and acute, traumatic aortic tears-with reasonable success. ${ }^{6-10}$ Several recently published guidelines favor TEVAR over surgery for the treatment (when feasible) of acute catastrophe of the descending thoracic aorta. ${ }^{11,12}$ An attempt to further broaden the indications for TEVAR to include uncomplicated chronic type B aortic dissection was undertaken with the Investigation of Stent Grafts in Patients with Type B Aortic Dissection trial (INSTEAD; comparing TEVAR to optimal medical management), the only randomized controlled trial of TEVAR ever completed; however, no improvement in 2or 5-year all-cause mortality was shown, probably because of the high incidence of nonaneurysmal death (and thus the low overall survival benefit of TEVAR) in patients with uncomplicated type B aortic dissection. ${ }^{13,14}$ Several 


\section{Abbreviations and Acronyms \\ $\mathrm{CPT}=$ Current Procedural Terminology \\ FDA $=$ US Food and Drug Administration \\ ICD-9 = International Classification of Diseases, ninth revision \\ TEVAR $=$ thoracic endovascular aortic repair}

commercial devices have been approved for TEVAR, which have all been associated with good freedom from aneurysm-related death, although midterm all-cause mortality remains suboptimal. ${ }^{15-20}$

Since FDA approval made TEVAR available for general clinical use in the United States, analyses of large US registries such as the Nationwide Inpatient Sample and US Medicare database have shown a dramatic rise in the use of TEVAR, although the rate of open repair of descending thoracic aortic aneurysms did not decrease appreciably. ${ }^{2,3}$ In particular, the US Medicare database provides unprecedented access to patient demographics, comorbidities, and operative characteristics while also providing long-term survival data; several studies have used this database to assess midterm outcomes after TEVAR and open repair of both descending thoracic aortic aneurysm and type B dissection. ${ }^{21,22}$ However, although specific subsets of TEVAR recipients have been studied, a broad overview is lacking of how TEVAR has been applied in US Medicare patients since the first TEVAR devices received FDA approval, particularly with respect to which types of aortic disease are being treated with TEVAR. Furthermore, prior analyses of the US Medicare database have not fully taken advantage of the variables available in the Medicare database to evaluate surgical complexity (eg, how arterial access was obtained, whether the left subclavian artery required coverage, whether additional procedures were required). The aim of our study was to evaluate the application of TEVAR in the US Medicare population since its approval by the FDA, with a particular focus on operative characteristics and making sure to stratify patients by aortic disease.

\section{METHODS}

\section{Data Collection and Study Population}

We retrospectively reviewed data from the Centers for Medicare and Medicaid Services administrative database from 2005 to 2010. Patient demographics and survival data were obtained from the Beneficiary Summary file; International Classification of Diseases, ninth revision (ICD9) diagnosis codes pertaining to the descending thoracic aorta and ICD-9 procedural codes pertaining to TEVAR were obtained from the MedPar file; patient comorbidities were obtained from the Chronic Conditions file; and surgeon billed Current Procedural Terminology (CPT) codes pertaining to prior and current surgical procedures were obtained from the Carrier file. Using data from the Chronic Conditions file to define patient comorbidities has been validated, particularly for conditions requiring regular physician follow-up, which is the case for TEVAR-treated descending thoracic aortic disease. ${ }^{23}$ Patients with an ICD-9 procedural code of 39.73 or a CPT code of 33880, 33881, $33883,33884,33886,75956,75957,75958$, or 75959 were designated as having undergone TEVAR and were included in our analysis $(\mathrm{N}=11,996){ }^{24,25}$

\section{Determination of Aortic Disease}

An algorithm was used to determine each patient's aortic disease from the ICD-9 diagnosis codes recorded at the index admission and at prior admissions. We classified patients as having 1 of 8 underlying aortic diseases: descending thoracic aortic rupture at the current admission (441.1, 441.3, $441.5,441.6)$, thoracic aortic trauma at the current admission (901.0, 902.0), chronic aortic dissection (ie, aortic dissection diagnosed before the current admission) (441.0, 441.00, 441.01, 441.02, 441.03), acute aortic dissection (ie, aortic dissection not diagnosed before the current admission), thoracoabdominal aortic aneurysm (diagnosed either previously or at the current admission) (441.7), thoracic aortic aneurysm with concomitant abdominal aortic aneurysm (diagnosed either previously or at the current admission) $(441.2,441.4)$, isolated thoracic aortic aneurysm $(441.2$, in current or prior diagnoses), and descending thoracic aortic disease without a recorded diagnosis (441.9 or no other ICD-9 code previously described).

\section{Statistical Analysis}

We identified 999 US hospitals that performed between 1 and 477 TEVARs in Medicare patients during the study period. Because rigorous studies of both center volume and center-specific variation have shown them to be independently associated with postprocedural outcomes, ${ }^{26}$ we included both variables in our analysis. A hospital was considered high volume if it performed $\geq 100$ TEVARs in Medicare patients ( 15 hospitals met this criteria), and moderate volume if it performed 20 to 99 TEVARs in Medicare patients (122 hospitals met this criteria) over the study period (hospital Medicare TEVAR volume was used as a surrogate for overall hospital volume). Hospital-specific variation with respect to post-TEVAR survival was modeled as a random effect in a multivariate mixed-effect Cox model ${ }^{27}$ that included all variables listed in Table 1 as covariates; this interhospital variation was statistically significant (likelihood-ratio test of $\theta=0: 10.78 ; P=.001)$, implying that hospital-specific variation is associated with post-TEVAR survival. In our multivariable analysis, in an effort to show the importance of hospital-specific variation, an independent hazard for postprocedural death was calculated for all 999 hospitals, and a dichotomous variable representing hospitals among the top third of post-TEVAR survival was generated to account for hospital variation in subsequent analyses.

The primary end point was all-cause mortality. Patients' vital status and date of death were validated with National Death Index data from 2005-2008 and with an internal Medicare determination of death (which itself informs the Social Security Death Master File) in patients for whom National Death Index data was unavailable; agreement between the National Death Index and Medicare death composite for vital status and date of death was $>99 \%{ }^{28}$ Post-TEVAR survival distributions were estimated with the nonparametric Kaplan-Meier method ${ }^{29}$; the log-rank test ${ }^{30}$ was used to compare differences between survival distributions. Post-TEVAR survival for the entire cohort was compared to an age-/sex-/race-matched general US population cohort (data from the National Center for Health Statistics) using the 1-sample log-rank test as described by Finkelstein and colleagues. ${ }^{31}$

Univariate and multivariable Cox proportional hazards regression analyses $^{32}$ assessed the effect of demographics, descending thoracic aortic disease, clinical comorbidities, prior operations, and surgical complexity on post-TEVAR survival. The proportional hazards assumption was tested with the Grambsch/Therneau method of plotting scaled Schoenfeld residuals ${ }^{33}$; no significant deviations from the proportional hazards assumption were noted. Interactions between variables were explored, without any significant findings. Purposeful selection of covariates was used to create a multivariable model $^{34}$; variables hypothesized or previously shown to have clinical significance in TEVAR recipients were included along with novel variables that were plausibly significant $(P \leq .20)$ on univariate analysis. Variables insignificant $(P>.05)$ by the Wald test in our multivariable models but that were plausible predictors of survival were included in our final 
TABLE 1. Characteristics of thoracic endovascular aortic repair (TEVAR) recipients, both as a whole and stratified by whether Current Procedural Terminology (CPT) codes were available in the Medicare database

\begin{tabular}{|c|c|c|c|c|}
\hline Characteristic & $\begin{array}{c}\text { Entire cohort } \\
(N=11,966)\end{array}$ & $\begin{array}{c}\text { With CPT codes } \\
\quad(n=7895)\end{array}$ & $\begin{array}{l}\text { Without CPT codes } \\
\quad(n=4071) \\
\end{array}$ & $P$ value \\
\hline \multicolumn{5}{|l|}{ Demographic } \\
\hline Age at operation, $y$ & $74.3 \pm 8.8$ & $74.7 \pm 8.9$ & $73.7 \pm 8.7$ & $<.001$ \\
\hline Gender, male & $6611(55.3)$ & $4270(54.1)$ & $2341(57.5)$ & $<.001$ \\
\hline Race, white & $9919(82.9)$ & $6600(83.6)$ & $3319(81.5)$ & .004 \\
\hline Race, African American & $1415(11.8)$ & $900(11.4)$ & 515 (12.7) & .05 \\
\hline Race, Asian & $224(1.9)$ & $145(1.8)$ & $79(1.9)$ & .69 \\
\hline Race, Hispanic & $172(1.4)$ & $106(1.3)$ & $66(1.6)$ & .23 \\
\hline Insurance in addition to Medicare & $2008(16.8)$ & $206(2.6)$ & $1802(44.3)$ & $<.001$ \\
\hline \multicolumn{5}{|l|}{ Aortic disease } \\
\hline Chronic aortic dissection & $1637(13.7)$ & $1165(14.8)$ & $472(11.6)$ & $<.001$ \\
\hline Acute aortic dissection & $1217(10.2)$ & $700(8.9)$ & $517(12.7)$ & $<.001$ \\
\hline Thoracic aortic aneurysm & $3751(31.4)$ & $2467(31.3)$ & $1284(31.5)$ & .74 \\
\hline Thoracoabdominal aortic aneurysm & $2329(19.5)$ & $1587(20.1)$ & $742(18.2)$ & .01 \\
\hline Thoracic and abdominal aortic aneurysm & $925(7.7)$ & $665(8.4)$ & $260(6.4)$ & $<.001$ \\
\hline Rupture & $1055(8.8)$ & $710(9.0)$ & $345(8.5)$ & .34 \\
\hline Trauma & $317(2.6)$ & $216(2.7)$ & $101(2.5)$ & .41 \\
\hline Missing diagnosis pertaining to the descending thoracic aorta & $735(6.1)$ & $385(4.9)$ & $350(8.6)$ & $<.001$ \\
\hline \multicolumn{5}{|l|}{ Comorbidities } \\
\hline History of myocardial infarction & $733(6.1)$ & $556(7.0)$ & $177(4.4)$ & $<.001$ \\
\hline Ischemic heart disease & $8417(70.3)$ & $6158(78.0)$ & $2259(55.5)$ & $<.001$ \\
\hline Congestive heart failure & $4829(40.4)$ & $3612(45.8)$ & $1217(29.9)$ & $<.001$ \\
\hline Atrial fibrillation & $2315(19.4)$ & $1758(22.3)$ & $557(13.7)$ & $<.001$ \\
\hline Hyperlipidemia & $8581(71.7)$ & $6261(79.3)$ & $2320(57.0)$ & $<.001$ \\
\hline Hypertension & $10,178(85.1)$ & $7361(93.2)$ & $2817(69.2)$ & $<.001$ \\
\hline Chronic obstructive pulmonary disease & $5390(45.0)$ & 4077 (51.6) & $1313(32.3)$ & $<.001$ \\
\hline Chronic kidney disease & $3893(32.5)$ & $2986(37.8)$ & $907(22.3)$ & $<.001$ \\
\hline End-stage renal disease & $510(4.3)$ & $367(4.7)$ & $143(3.5)$ & .004 \\
\hline Diabetes & $3403(28.4)$ & $2548(32.3)$ & $855(21.0)$ & $<.001$ \\
\hline Anemia & $6566(54.9)$ & $4921(62.3)$ & $1645(40.4)$ & $<.001$ \\
\hline Stroke/transient ischemic attack & $2265(18.9)$ & $1722(21.8)$ & $543(13.3)$ & $<.001$ \\
\hline Alzheimer's/dementia & $967(8.1)$ & $755(9.6)$ & $212(5.2)$ & $<.001$ \\
\hline History of cancer & $1801(15.1)$ & $1349(17.1)$ & $452(11.1)$ & $<.001$ \\
\hline \multicolumn{5}{|l|}{ Operative center characteristics } \\
\hline Year of operation & $2008(2007-2009)$ & $2008(2007-2009)$ & $2008(2007-2010)$ & \\
\hline High-volume TEVAR hospital* & $2798(23.4)$ & $1980(25.1)$ & $818(20.1)$ & $<.001$ \\
\hline Medium- or high-volume TEVAR hospital $\dagger$ & $7511(62.8)$ & $5185(65.7)$ & $2326(57.1)$ & $<.001$ \\
\hline High-performing TEVAR hospital & $5328(44.5)$ & $3620(45.8)$ & $1708(42.0)$ & $<.001$ \\
\hline
\end{tabular}

Values are presented as n (\%) or median (interquartile range). Boldface type indicates $P$ values $<.05$. CPT, Current Procedural Terminology; TEVAR, thoracic endovascular aortic repair. *More than 100 TEVARs in Medicare patients from 2005-2010. †More than 20 TEVARs in Medicare patients from 2005-2010.

models; covariate selection was also guided by optimizing the Akaike information criterion. ${ }^{35}$ Two separate models were created: 1 for the entire cohort $(\mathrm{N}=11,966)$, and 1 for all patients for whom CPT codes were available $(\mathrm{n}=7895)$. Covariates used in the final model for the entire cohort included age, gender, race, insurance status, previous myocardial infarction, congestive heart failure, atrial fibrillation, hypertension, chronic obstructive pulmonary disease, chronic kidney disease, end-stage renal disease necessitating hemodialysis, diabetes, stroke or transient ischemic attack, Alzheimer's disease or dementia, history of cancer, aortic disease, aortic rupture, hospital volume, and hospital effect. Covariates used in the final model for patients with CPT codes included the aforementioned demographic, comorbidity, and hospital variables, along with method of stent graft deployment, whether the stent graft covered the left subclavian artery, concomitant cardiac surgery, concomitant thoracic aortic surgery, concomitant abdominal aortic surgery, concomitant visceral abdominal artery reimplantation, concomitant head- or neckvessel surgery, and lumbar drain placement.
Means are presented with standard deviations, and hazard ratios are presented with $95 \%$ confidence intervals. Because this study was exploratory, no adjustments were made for multiple comparisons. ${ }^{36}$ Analyses were conducted with Stata software (version 13, StataCorp LP, College Station, Tex).

\section{RESULTS \\ Patient Characteristics}

Of 11,966 patients who underwent TEVAR (Table 1), 1055 had an acute aortic rupture, 317 had traumatic aortic injury, 1637 had chronic aortic dissection, 1217 had acute aortic dissection, 2329 had thoracoabdominal aneurysm, 925 had thoracic aortic aneurysm with concomitant abdominal aortic aneurysm, and 3751 had thoracic aortic aneurysm alone. In 

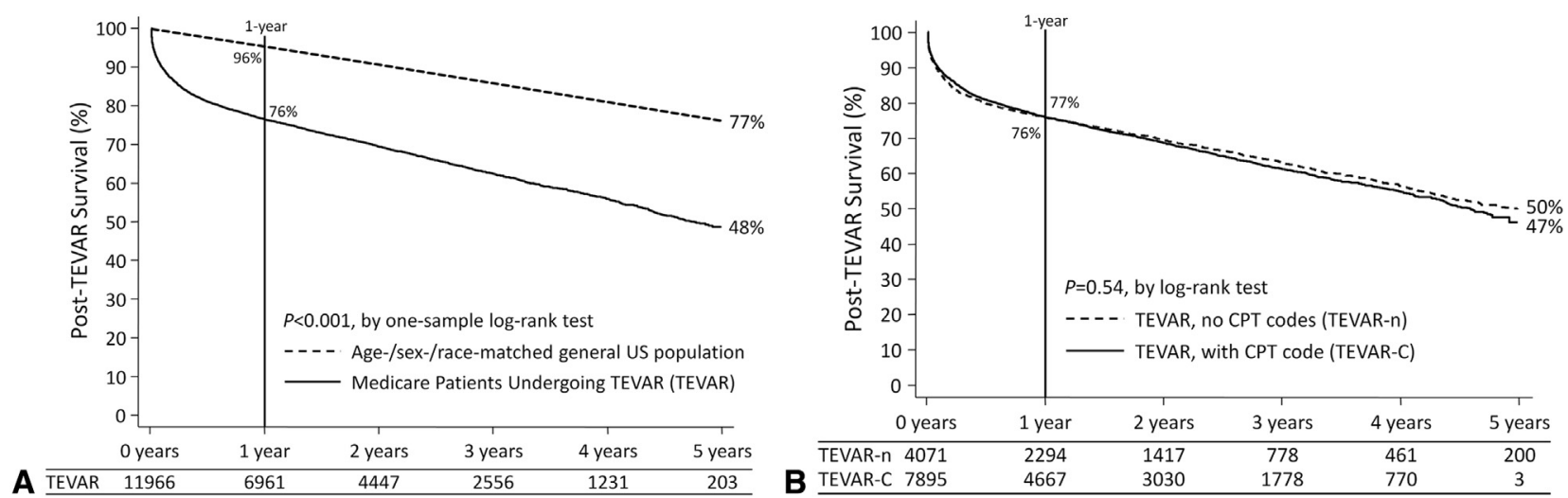

FIGURE 1. Survival after thoracic endovascular aortic repair (TEVAR) in Medicare patients, modeled according to the Kaplan-Meier method. A, PostTEVAR survival for the entire cohort compared with an age-/sex-/race-matched general US population cohort. B, Post-TEVAR survival for patients with and without Current Procedural Terminology (CPT) codes.

the remaining 735 patients, we could not ascertain a diagnosis of the descending thoracic aorta.

The overall cohort was stratified according to whether patients' CPT codes were available $(\mathrm{n}=7895)$ or unavailable $(\mathrm{n}=4071)$. These 2 groups differed substantially with regard to most of the patient characteristics we assessed; for example, patients without CPT codes
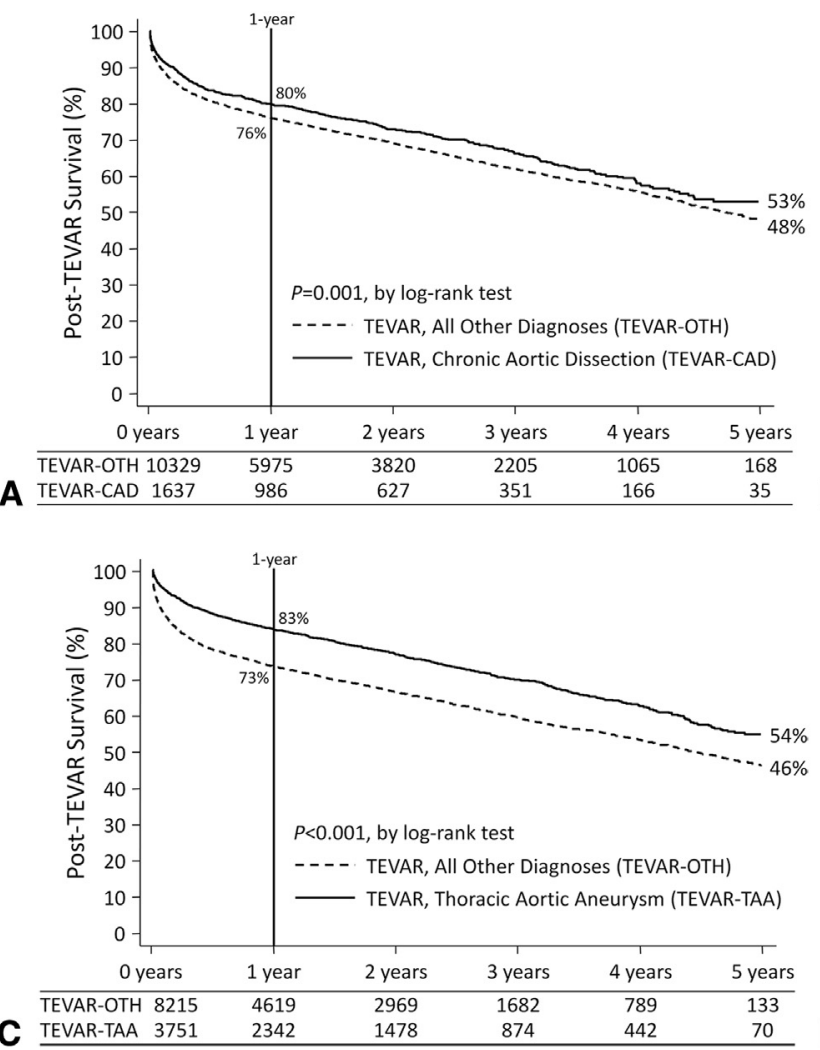

had fewer comorbidities and were more likely to have other health insurance in addition to Medicare.

\section{Post-TEVAR Survival}

After TEVAR, patients had a median survival of 57.6 months (95\% confidence interval, 54.9-61.3 months) (Figure 1, A). Post-TEVAR survival was comparable
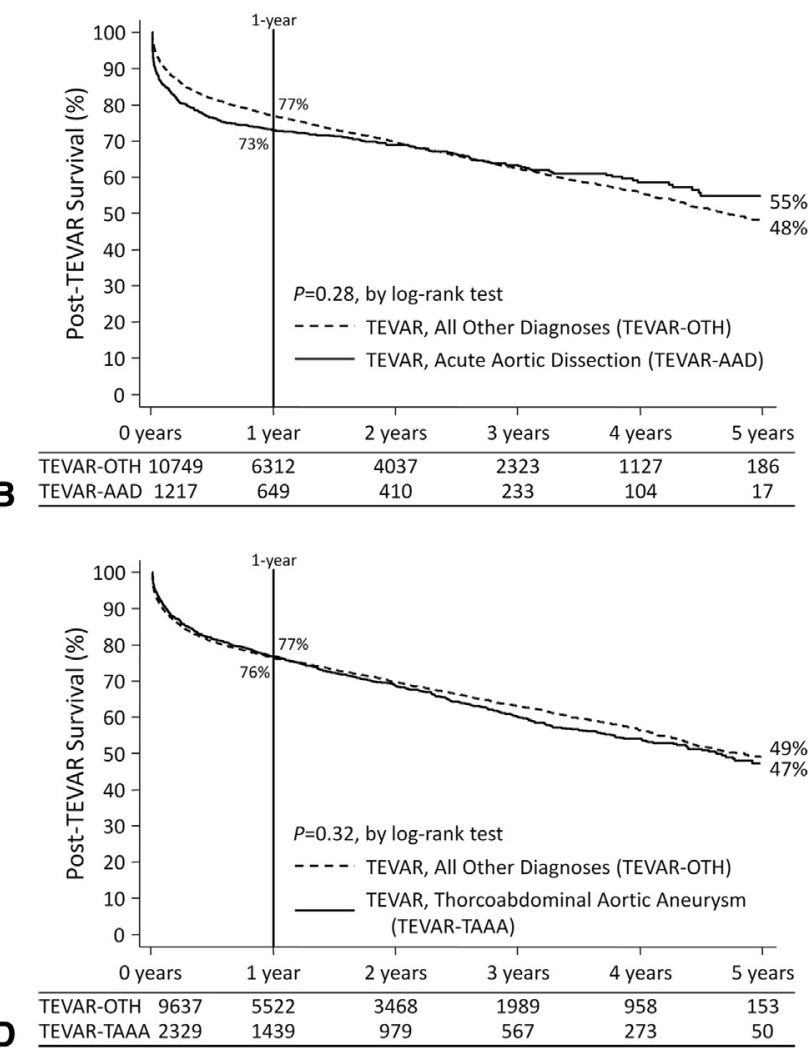

FIGURE 2. A comparison of Kaplan-Meier survival among the different diseases of the descending thoracic aorta treated with thoracic endovascular aortic repair (TEVAR). For each graph, the survival of patients with the diagnosis of interest is compared with that of all other patients combined. A, Post-TEVAR survival for chronic aortic dissection. B, Post-TEVAR survival for acute aortic dissection. C, Post-TEVAR survival for thoracic aortic aneurysm. D, Post-TEVAR survival for thoracoabdominal aortic aneurysm. E, Post-TEVAR survival for thoracic aortic aneurysm with concomitant abdominal aortic aneurysm. F, Post-TEVAR survival for aortic rupture. G, Post-TEVAR survival for aortic trauma. H, Post-TEVAR survival for descending thoracic aortic disease but no recorded diagnosis. 

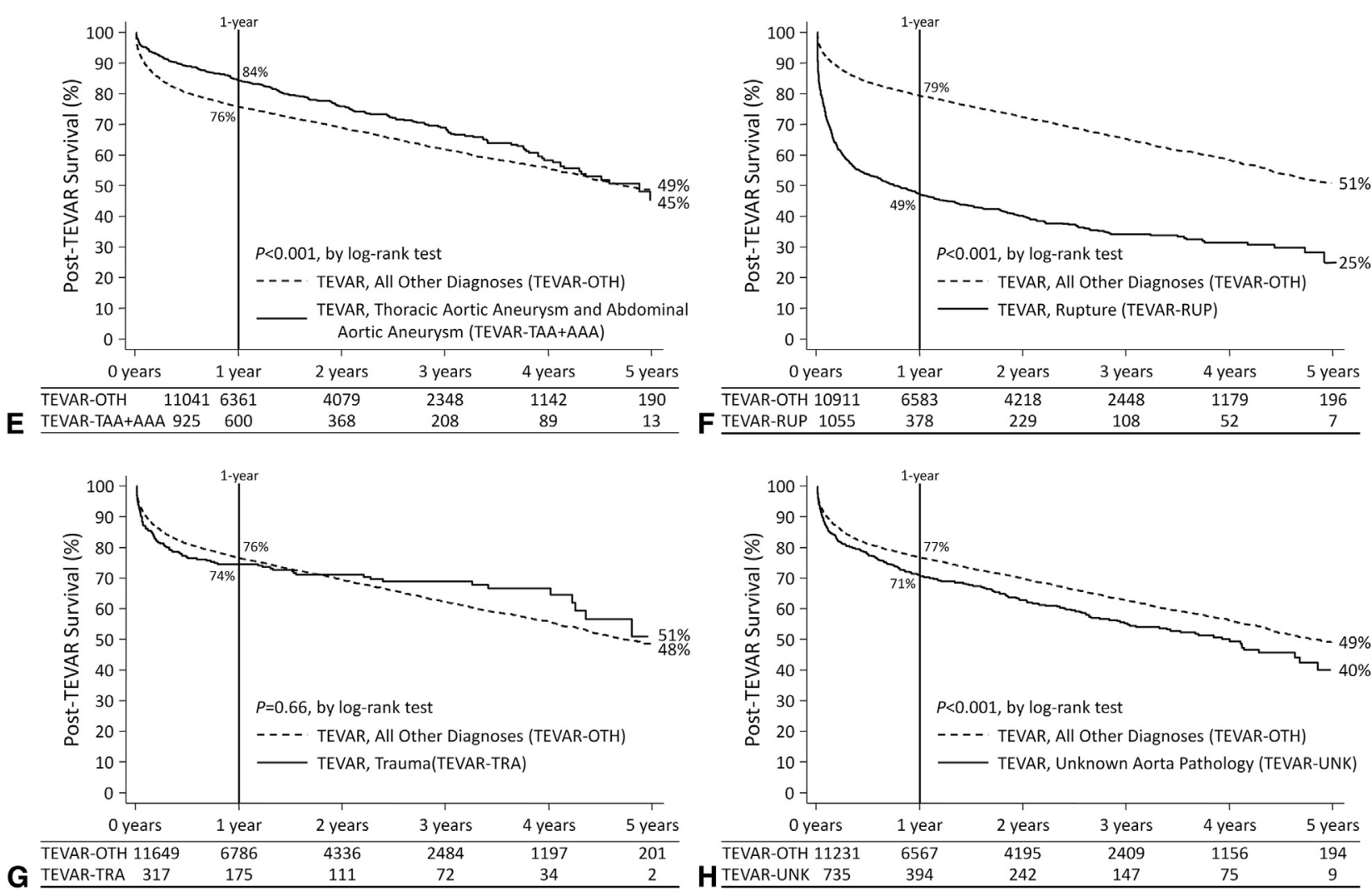

FIGURE 2. (continued).

between patients with and without CPT codes (56.3 vs 59.5 months; $P=.54$ by log-rank) (Figure $1, B$ ). In contrast, different diagnoses were associated with clear differences in survival (Figure 2). The late hazard of post-TEVAR death also differed by descending thoracic aortic disease type (Figure 3). The highest perioperative death rates were noted in patients with aortic rupture, acute aortic dissection, and aortic trauma. However, acute aortic dissection and aortic trauma were also associated with the lowest late postoperative death rates.

\section{Predictors of Post-TEVAR Survival for Entire Cohort}

Table 2 shows univariate and multivariable hazard ratios for death after TEVAR for all variables not involving CPT codes. Twenty variables were included in our multivariable model of predictors of survival after TEVAR. Factors associated with worse survival included older age, additional insurance (eg, a health maintenance organization), history of myocardial infarction, congestive heart failure, atrial fibrillation, chronic obstructive pulmonary disease, chronic kidney disease, end-stage renal disease necessitating hemodialysis, anemia, history of transient ischemic attack or stroke, Alzheimer's disease and/or dementia, history of cancer, and aortic rupture. Predictors of improved survival included a diagnosis of hypertension, isolated thoracic aortic aneurysm as the underlying aortic disease, and undergoing TEVAR at a high-performing TEVAR hospital.

\section{Characteristics of Patients With CPT Codes, Stratified by Aortic Disease}

Of the 7895 patients with CPT codes (Table 3), $710 \mathrm{had}$ aortic rupture, 216 sustained a traumatic aortic injury, 1165 had chronic aortic dissection, 700 had acute aortic dissection, 1587 had thoracoabdominal aortic aneurysm, 665 had thoracic aortic aneurysm with concomitant abdominal aortic aneurysm, and 2467 had thoracic aortic aneurysm. Significant differences existed among patients with different descending thoracic aortic diseases, particularly with respect to patient comorbidities, previous operations, and the need for concurrent procedures.

\section{Predictors of Post-TEVAR Survival for the Subcohort With CPT Codes}

Table 4 shows univariate and multivariable hazard ratios for death after TEVAR for the subcohort of patients with CPT codes. Thirty variables were included in our multivariable model of predictors of survival after TEVAR (Table 3). Factors associated with worse survival included older age; male gender; history of myocardial infarction; congestive heart failure; atrial fibrillation; chronic obstructive pulmonary disease; chronic kidney disease; 

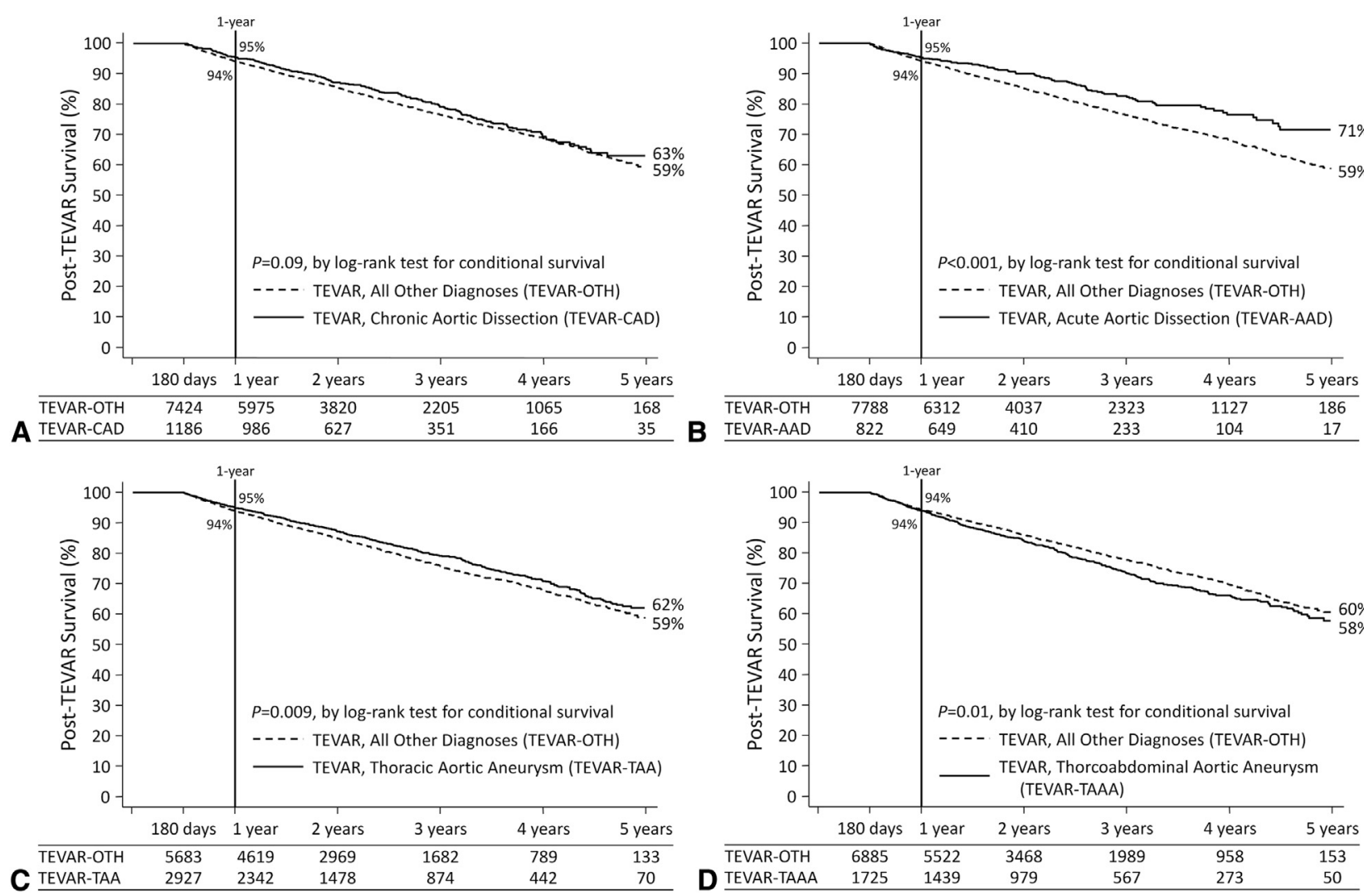

FIGURE 3. A comparison of conditional Kaplan-Meier survival (survival among patients who survived the perioperative period; that is, alive at 180 days) among the different diseases of the descending thoracic aorta treated with thoracic endovascular aortic repair (TEVAR). For each graph, the survival of patients with the diagnosis of interest is compared with that of all other patients combined. A, Post-TEVAR 180-day conditional survival for patients with chronic aortic dissection. B, Post-TEVAR 180-day conditional survival for patients with acute aortic dissection. C, Post-TEVAR 180-day conditional survival for patients with thoracic aortic aneurysm. D, Post-TEVAR 180-day conditional survival for patients with thoracoabdominal aortic aneurysm. E, Post-TEVAR 180-day conditional survival for patients with thoracic aortic aneurysm with concomitant abdominal aortic aneurysm. F, Post-TEVAR 180-day conditional survival for patients with aortic rupture. G, Post-TEVAR 180-day conditional survival for patients with aortic trauma. H, Post-TEVAR 180-day conditional survival for patients with descending thoracic aortic disease but no recorded diagnosis.

end-stage renal disease necessitating hemodialysis; anemia; history of transient ischemic attack or stroke; Alzheimer's disease or dementia; history of cancer; previous TEVAR or endovascular aneurysm repair; and concurrent cardiac, thoracic aortic, abdominal aortic, visceral abdominal aorta branch-artery, and head or neck artery surgery. Predictors of improved survival included having an isolated thoracic aortic aneurysm, having undergone a previous open thoracic aortic procedure, undergoing TEVAR at a high-performing TEVAR hospital, and receiving an aortic graft that did not cover the left subclavian artery.

\section{DISCUSSION}

Our study of predictors of midterm survival in Medicare TEVAR patients produced four particularly noteworthy findings. First, hospital volume was not associated with survival. However, there was a clear and significant hospital effect: The hazard of death at high-performing hospitals was about $50 \%$ of what it was at other hospitals. Whether patient selection, operative competence, postoperative clinical excellence, high-quality long-term management, or some combination of these factors underlies the hospital effect is unknown and warrants further study.

Second, the early and late hazard of post-TEVAR death varied by disease type. For example, although patients who underwent TEVAR for acute aortic dissection or aortic trauma had a high incidence of periprocedural death, patients with these diseases also had the lowest incidence of late death ( $\geq 180$ days); meanwhile, isolated thoracic aortic aneurysm was associated with the lowest early incidence of death, but a comparatively higher incidence of late death. Aortic rupture was associated with the worst incidence of both early and late hazard of death.

Third, greater operative complexity was associated with worse postprocedural survival. The simplest aortic disease (isolated thoracic aortic aneurysm) was associated with the best early postprocedural survival, particularly if treatment did not require covering the left subclavian artery. 

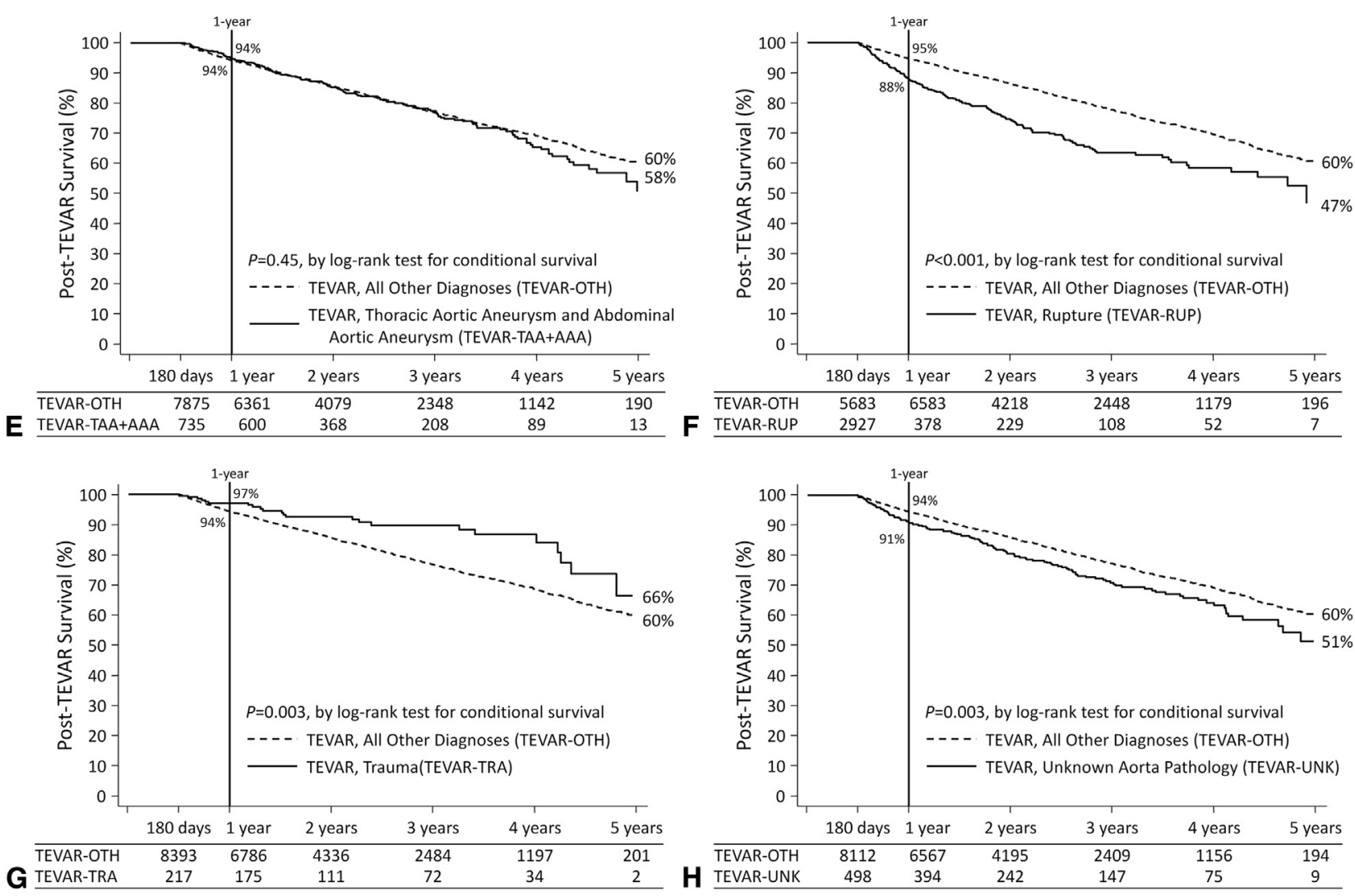

FIGURE 3. (continued)

Fourth and finally, records of Medicare patients without CPT codes had fewer documented comorbidities, even though these patients had similar post-TEVAR survival to patients with CPT codes. Thus, studies that do not differentiate between the patients with and without CPT codes are subject to selection bias.

\section{Interhospital Variability in Post-TEVAR Survival}

Somewhat surprisingly, we found no correlation between hospital TEVAR volume (at least in Medicare beneficiaries) and post-TEVAR survival. However, there was clear and significant interhospital variability with respect to survival, even when rigorous multivariable analysis was performed to control for patient comorbidities and operative characteristics. The importance of interhospital variability has been previously shown for other surgical procedures. ${ }^{26}$ Unfortunately, the Medicare database includes no data that could inform us whether patient selection, operative competence, the quality of postoperative clinical care or long-term management, or some combination of these factors underlies this important hospital effect.

\section{Aortic Diseases Treated by TEVAR}

TEVAR was applied to the spectrum of aortic disease, from isolated thoracic aortic aneurysm to aortic rupture, chronic aortic dissection, and even thoracoabdominal aneurysm. As expected, patients with acute catastrophes of the aorta such as acute aortic dissection or aortic trauma had fewer comorbidities than patients with aneurysms or chronic aortic dissection. The prevalence of prior cardiac, aortic, or peripheral arterial surgery also varied by aortic disease; patients with thoracoabdominal aneurysm, thoracic aortic aneurysm with concomitant abdominal aortic aneurysm, or chronic aortic dissection were more likely to have undergone a previous endovascular aneurysm repair, open abdominal aortic operation, or lower-extremity bypass than patients with other aortic diseases. Meanwhile, patients with chronic aortic dissection were more likely than others to have undergone a previous open thoracic aortic repair or TEVAR. Patients with more complex aortic disease also required more complex procedures. For example, patients with chronic aortic dissection were most unlikely to undergo TEVAR requiring subclavian artery coverage and concomitant head-neck artery bypass, whereas patients with thoracoabdominal aneurysm were most likely to require EVAR, open abdominal aortic repair, or abdominal aorta visceral artery branch surgery. Patients with acute aortic dissection, rupture of the aorta, or aortic trauma were less likely than other patients to require a lumbar drain, underscoring the more emergent nature of these diseases. 
TABLE 2. Predictors of survival following thoracic endovascular aortic repair (TEVAR) for the entire cohort $(\mathrm{N}=11,966)$

\begin{tabular}{|c|c|c|c|c|}
\hline Predictor & $\begin{array}{l}\text { Multivariable hazard } \\
\text { ratio }(95 \% \mathrm{CI})\end{array}$ & $P$ value* & $\begin{array}{l}\text { Univariate hazard } \\
\text { ratio }(95 \% \mathrm{CI})\end{array}$ & $P$ value $\dagger$ \\
\hline \multicolumn{5}{|l|}{ Demographic characteristic } \\
\hline Age at operation, $y$ & $1.029(1.025-1.034)$ & $<.001$ & $1.034(1.030-1.038)$ & $<.001$ \\
\hline Gender, male & $1.06(0.99-1.14)$ & .06 & $1.03(0.96-1.09)$ & .44 \\
\hline Race, white & & & $0.95(0.87-1.03)$ & .20 \\
\hline Race (African American) & $1.09(0.98-1.20)$ & .10 & $1.13(1.03-1.24)$ & .01 \\
\hline Race (Asian) & & & $0.93(0.74-1.19)$ & .58 \\
\hline Race (Hispanic) & & & $0.90(0.68-1.20)$ & .47 \\
\hline Insurance in addition to Medicare & $1.21(1.09-1.34)$ & $<.001$ & $0.97(0.89-1.07)$ & .59 \\
\hline \multicolumn{5}{|l|}{ Comorbidities } \\
\hline History of myocardial infarction & $1.14(1.01-1.28)$ & .03 & $1.42(1.27-1.60)$ & $<.001$ \\
\hline Ischemic heart disease & & & $1.30(1.21-1.40)$ & $<.001$ \\
\hline Congestive heart failure & $1.24(1.15-1.33)$ & $<.001$ & $1.64(1.54-1.75)$ & $<.001$ \\
\hline Atrial fibrillation & $1.14(1.05-1.23)$ & .001 & $1.45(1.35-1.56)$ & $<.001$ \\
\hline Hyperlipidemia & & & $1.06(0.99-1.14)$ & .12 \\
\hline Hypertension & $0.83(0.74-0.93)$ & .002 & $1.32(1.19-1.45)$ & $<.001$ \\
\hline Chronic obstructive pulmonary disease & $1.24(1.16-1.33)$ & $<.001$ & $1.39(1.31-1.48)$ & $<.001$ \\
\hline Chronic kidney disease & $1.36(1.27-1.47)$ & $<.001$ & $1.74(1.63-1.85)$ & $<.001$ \\
\hline End-stage renal disease & $1.93(1.70-2.20)$ & $<.001$ & $2.27(2.02-2.56)$ & $<.001$ \\
\hline Diabetes & $0.97(0.90-1.04)$ & .42 & $1.17(1.10-1.25)$ & $<.001$ \\
\hline Anemia & $1.21(1.12-1.30)$ & $<.001$ & $1.61(1.50-1.72)$ & $<.001$ \\
\hline Stroke/transient ischemic attack & $1.13(1.05-1.22)$ & .002 & $1.44(1.33-1.54)$ & $<.001$ \\
\hline Alzheimer's/dementia & $1.21(1.09-1.34)$ & $<.001$ & $1.72(1.56-1.90)$ & $<.001$ \\
\hline History of cancer & $1.11(1.02-1.21)$ & .01 & $1.25(1.15-1.36)$ & $<.001$ \\
\hline \multicolumn{5}{|l|}{ Diagnosis } \\
\hline Chronic aortic dissection & & & $0.85(0.77-0.94)$ & .001 \\
\hline Acute aortic dissection & & & $1.06(0.95-1.18)$ & .28 \\
\hline Thoracic aortic aneurysm & $0.78(0.72-0.84)$ & $<.001$ & $0.66(0.61-0.71)$ & $<.001$ \\
\hline Thoracoabdominal aortic aneurysm & & & $1.04(0.96-1.12)$ & .32 \\
\hline $\begin{array}{l}\text { Concomitant thoracic aortic aneurysm and abdominal } \\
\text { aortic aneurysm }\end{array}$ & & & $0.76(0.67-0.86)$ & $<.001$ \\
\hline Rupture & $2.52(2.31-2.76)$ & $<.001$ & $2.87(2.64-2.13)$ & $<.001$ \\
\hline Aortic trauma & & & $0.96(0.78-1.17)$ & .66 \\
\hline Missing thoracic aortic diagnosis & & & $1.26(1.12-1.42)$ & $<.001$ \\
\hline \multicolumn{5}{|l|}{ Operative center characteristics } \\
\hline Year of operation & & & $1.01(0.98-1.03)$ & .61 \\
\hline High-volume TEVAR hospital $\ddagger$ & $1.02(0.95-1.10)$ & .58 & $1.10(1.02-1.18)$ & .01 \\
\hline Medium- to high-volume TEVAR hospital $\S$ & & & $1.05(0.99-1.13)$ & .12 \\
\hline High-performing TEVAR hospital & $0.51(0.48-0.55)$ & $<.001$ & $0.55(0.52-0.59)$ & $<.001$ \\
\hline
\end{tabular}

Boldface indicates $P$ values $<.05$. CI, Confidence interval; TEVAR, thoracic endovascular aortic repair. * $P$ value obtained from multivariable Cox proportional hazards regression model of predictors of post-TEVAR survival, as described in the Methods. $\dagger P$ value obtained from univariate Cox proportional hazards regression model of post-TEVAR survival. $\ddagger$ More than 100 TEVARs in Medicare patients from 2005-2010. §More than 20 TEVARs in Medicare patients from 2005-2010.

\section{Early and Late Hazard of Death Among TEVAR Recipients}

The median survival of 57.6 months (1- and 5-year survival of $76 \%$ and $48 \%$ ) in this cohort is consistent with those found in previous analyses of midterm post-TEVAR outcomes. ${ }^{4,5}$ Perioperative mortality varied by diagnosis. More complex or acute diagnoses were associated with worse perioperative survival, whereas the least complex condition-isolated thoracic aortic aneurysm that did not require stent-graft coverage of the left subclavian arterywas associated with the highest rate of perioperative survival. As has been previously been shown, ${ }^{21}$ aortic rupture was associated with the worst early, midterm, and late survival. Interestingly, although patients with acute aortic dissection and aortic trauma had poor periprocedural outcomes, they also had the lowest late postoperative death rates. We suggest that these patients represent a fundamentally less sick population than patients with chronic aortic dissection, thoracic aortic aneurysm, or thoracoabdominal aortic aneurysm; this intuition is supported by the younger ages and smaller number of comorbidities noted in acute aortic dissection and aortic trauma patients.

The high late mortality rate of Medicare TEVAR recipients was perhaps the most disconcerting finding. In patients who survived to 180 days (assessed by using conditional survival) (Figure 3), well beyond the perioperative risk 
TABLE 3. Demographic, comorbid, and operative characteristics of subcohort of thoracic endovascular aortic repair (TEVAR) recipients with Current Procedural Terminology codes $(n=7895)$

\begin{tabular}{|c|c|c|c|c|c|c|c|c|}
\hline Characteristic & $\begin{array}{l}\text { Chronic aortic } \\
\text { dissection } \\
(\mathrm{n}=\mathbf{1 1 6 5}) \\
\end{array}$ & $\begin{array}{l}\text { Acute aortic } \\
\text { dissection } \\
(\mathbf{n}=700) \\
\end{array}$ & $\begin{array}{c}\text { Thoracic aortic } \\
\text { aneurysm } \\
(\mathrm{n}=\mathbf{2 4 6 7 )}\end{array}$ & $\begin{array}{c}\text { Thoraco- } \\
\text { abdominal } \\
\text { aneurysm } \\
(\mathbf{n}=\mathbf{1 5 8 7 )} \\
\end{array}$ & $\begin{array}{c}\text { Thoracic } \\
\text { aortic aneurysm } \\
\text { plus abdominal } \\
\text { aortic aneurysm } \\
(\mathrm{n}=665) \\
\end{array}$ & $\begin{array}{c}\text { Rupture of } \\
\text { thoracic aorta } \\
(\mathbf{n}=\mathbf{7 1 0}) \\
\end{array}$ & $\begin{array}{c}\text { Trauma to } \\
\text { thoracic } \\
\text { aorta }(n=216) \\
\end{array}$ & $\begin{array}{c}\text { Missing } \\
\text { diagnosis } \\
(\mathbf{n}=\mathbf{3 8 5}) \\
\end{array}$ \\
\hline \multicolumn{9}{|l|}{ Demographic characteristic } \\
\hline Age at operation, y & $73.0 \pm 10.2$ & $72.6 \pm 10.3$ & $75.1 \pm 8.3$ & $75.2 \pm 7.4$ & $76.0 \pm 6.8$ & $77.0 \pm 8.3$ & $70.3 \pm 13.3$ & $74.5 \pm 8.8$ \\
\hline Gender, male & $625(53.7)$ & $380(54.3)$ & $1337(54.2)$ & $824(51.9)$ & $402(60.5)$ & $351(49.4)$ & $124(57.4)$ & $227(59.0)$ \\
\hline Race, white & $914(78.5)$ & $530(75.7)$ & $2079(84.3)$ & $1381(87.0)$ & $589(88.6)$ & $589(83.0)$ & 187 (86.6) & $331(86.0)$ \\
\hline Race, African American & $176(15.1)$ & $138(19.7)$ & $247(10.0)$ & $142(9.0)$ & $53(8.0)$ & $84(11.8)$ & $19(8.8)$ & $41(10.7)$ \\
\hline Race, Asian & $24(2.1)$ & $11(1.6)$ & $51(2.1)$ & $19(1.2)$ & $10(1.5)$ & $16(2.3)$ & $5(2.3)$ & $9(2.3)$ \\
\hline Race, Hispanic & $22(1.9)$ & $7(1.0)$ & $37(1.5)$ & $17(1.1)$ & $8(1.2)$ & $10(1.4)$ & $2(0.9)$ & $3(0.8)$ \\
\hline $\begin{array}{l}\text { Insurance in addition to } \\
\text { Medicare }\end{array}$ & $25(2.2)$ & $18(2.6)$ & $66(2.7)$ & $44(2.8)$ & $20(3.0)$ & $14(2.0)$ & $5(2.3)$ & $14(3.6)$ \\
\hline \multicolumn{9}{|l|}{ Comorbidities } \\
\hline $\begin{array}{l}\text { History of myocardial } \\
\text { infarction }\end{array}$ & $74(6.4)$ & $52(7.4)$ & $161(6.5)$ & $119(7.5)$ & $45(6.8)$ & $52(7.3)$ & $12(6.0)$ & $40(10.4)$ \\
\hline Ischemic heart disease & $929(79.7)$ & $464(66.3)$ & $1946(78.9)$ & $1290(81.3)$ & $558(83.9)$ & $536(75.5)$ & $114(52.8)$ & $231(83.4)$ \\
\hline Congestive heart failure & $576(49.4)$ & $288(41.1)$ & $1056(42.8)$ & $744(46.9)$ & $309(46.5)$ & $353(49.7)$ & $58(26.9)$ & $228(59.2)$ \\
\hline Atrial fibrillation & $310(26.6)$ & $140(20.0)$ & $500(20.3)$ & $340(21.4)$ & $151(22.7)$ & $168(23.7)$ & $34(15.7)$ & $115(29.9)$ \\
\hline Hyperlipidemia & $901(77.3)$ & $483(69.0)$ & $2003(81.2)$ & $1328(83.7)$ & $582(87.5)$ & $518(73.0)$ & $140(64.8)$ & $306(79.5)$ \\
\hline Hypertension & $1125(96.6)$ & $626(89.4)$ & $2298(93.2)$ & $1499(94.5)$ & $628(94.4)$ & $664(93.5)$ & $158(73.2)$ & $363(94.3)$ \\
\hline $\begin{array}{l}\text { Chronic obstructive } \\
\text { pulmonary disease }\end{array}$ & $528(45.3)$ & $241(34.4)$ & $1313(53.2)$ & $945(59.6)$ & $419(63.0)$ & $346(48.7)$ & $60(27.8)$ & $225(58.4)$ \\
\hline Chronic kidney disease & $478(41.0)$ & $205(29.3)$ & $832(33.7)$ & $685(43.2)$ & $261(39.3)$ & $299(42.1)$ & $47(26.8)$ & $179(46.5)$ \\
\hline End-stage renal disease & $63(5.4)$ & $30(4.3)$ & $82(3.3)$ & $78(4.9)$ & $20(3.0)$ & $57(8.0)$ & $3(1.4)$ & $34(8.8)$ \\
\hline Diabetes & $368(31.6)$ & $192(27.4)$ & $810(32.8)$ & $500(31.5)$ & $238(35.8)$ & $220(31.0)$ & $74(34.3)$ & $146(37.9)$ \\
\hline Anemia & $764(65.6)$ & $379(54.1)$ & $1479(60.0)$ & $995(62.7)$ & $411(61.8)$ & $498(70.1)$ & $119(55.1)$ & $276(71.7)$ \\
\hline $\begin{array}{l}\text { Stroke/transient } \\
\quad \text { ischemic attack }\end{array}$ & $270(23.2)$ & $110(15.7)$ & $531(21.5)$ & $339(21.4)$ & $158(23.8)$ & $181(25.5)$ & $36(16.7)$ & $97(25.2)$ \\
\hline Alzheimer's/dementia & $119(10.2)$ & $65(9.3)$ & $229(9.3)$ & $126(7.9)$ & $57(8.6)$ & $96(13.5)$ & $14(6.5)$ & $49(12.7)$ \\
\hline History of cancer & $161(13.8)$ & $96(13.7)$ & $461(18.7)$ & $292(18.4)$ & $140(21.1)$ & $117(16.5)$ & $22(10.2)$ & $60(15.6)$ \\
\hline \multicolumn{9}{|l|}{ Previous operations } \\
\hline Cardiac surgery* & $184(15.8)$ & $44(6.3)$ & $231(9.4)$ & $198(12.5)$ & $89(13.4)$ & $64(9.0)$ & $14(6.5)$ & $52(13.5)$ \\
\hline $\begin{array}{l}\text { Open thoracic aortic } \\
\text { surgery }\end{array}$ & $275(23.6)$ & $15(2.1)$ & $140(5.7)$ & $207(13.0)$ & $60(9.0)$ & $48(6.8)$ & $6(2.8)$ & $42(10.9)$ \\
\hline TEVAR & $25(2.2)$ & $8(1.1)$ & $21(0.9)$ & $14(0.9)$ & $7(1.1)$ & $9(1.3)$ & $2(0.9)$ & $7(1.8)$ \\
\hline $\begin{array}{l}\text { Open abdominal aortic } \\
\text { surgery }\end{array}$ & $146(12.5)$ & $1(0.1)$ & $15(0.6)$ & $245(15.4)$ & $206(31.0)$ & $45(6.3)$ & $0(0.0)$ & $101(26.2)$ \\
\hline $\begin{array}{l}\text { Endovascular aortic } \\
\quad \text { repair }\end{array}$ & $33(2.8)$ & $1(0.1)$ & $14(0.6)$ & $36(2.3)$ & $47(7.1)$ & $9(1.3)$ & $1(0.5)$ & $17(4.4)$ \\
\hline $\begin{array}{l}\text { Visceral abdominal aorta } \\
\text { branch surgery }\end{array}$ & $58(5.0)$ & $3(0.4)$ & $14(0.6)$ & $198(12.5)$ & $51(7.7)$ & $12(1.7)$ & $0(0.0)$ & $22(5.7)$ \\
\hline $\begin{array}{c}\text { Head/neck artery } \\
\text { operation } \dagger\end{array}$ & $178(15.3)$ & $39(5.6)$ & $262(10.6)$ & $158(10.0)$ & $62(9.3)$ & $18(2.5)$ & $10(4.6)$ & $36(9.4)$ \\
\hline $\begin{array}{l}\text { Upper-extremity artery } \\
\text { operation }\end{array}$ & $8(0.7)$ & $5(0.7)$ & $1(0.1)$ & $7(0.4)$ & $1(0.2)$ & $1(0.1)$ & $1(0.5)$ & $3(0.8)$ \\
\hline $\begin{array}{l}\text { Lower-extremity artery } \\
\text { operation } \S\end{array}$ & $26(2.2)$ & $9(1.3)$ & $30(1.2)$ & $76(4.8)$ & $33(5.0)$ & $18(2.5)$ & $1(0.5)$ & $24(6.2)$ \\
\hline \multicolumn{9}{|c|}{ Operative center characteristics } \\
\hline Year of operation & $2008(2007-2009)$ & 2008 (2007-2009) & $2009(2007-2010)$ & $2008(2007-2009)$ & $2008(2007-2009)$ & $2008(2007-2009)$ & $2009(2007-2010)$ & $2008(2007-2009)$ \\
\hline $\begin{array}{l}\text { High-volume TEVAR } \\
\quad \text { hospital } \|\end{array}$ & $375(32.2)$ & $178(25.4)$ & $508(20.6)$ & $473(29.8)$ & $140(21.1)$ & $192(27.0)$ & $36(16.7)$ & $78(20.3)$ \\
\hline $\begin{array}{l}\text { Medium- to high-volume } \\
\text { TEVAR hospital }\end{array}$ & $851(73.1)$ & $470(67.1)$ & $1522(61.7)$ & $1100(69.3)$ & $390(58.7)$ & $499(70.3)$ & $131(60.7)$ & $222(57.7)$ \\
\hline \multicolumn{9}{|l|}{ Operation characteristics } \\
\hline $\begin{array}{l}\text { TEVAR with subclavian } \\
\text { artery coverage }\end{array}$ & $458(39.3)$ & $271(38.7)$ & $837(33.9)$ & $393(24.8)$ & $192(28.9)$ & $230(32.4)$ & $81(37.5)$ & $115(29.9)$ \\
\hline $\begin{array}{r}\text { Prior or concomitant } \\
\text { head/neck bypass }\end{array}$ & $232(19.9)$ & $82(11.7)$ & $405(16.4)$ & $176(11.1)$ & $81(12.2)$ & $61(8.6)$ & $18(8.3)$ & $51(13.3)$ \\
\hline \multirow{2}{*}{$\begin{array}{l}\text { TEVAR without } \\
\text { subclavian artery } \\
\text { coverage }\end{array}$} & $693(59.5)$ & $434(62.0)$ & $1655(67.1)$ & $1145(72.2)$ & $468(70.4)$ & 488 (68.7) & $140(64.8)$ & $216(56.1)$ \\
\hline & $63(5.4)$ & $23(3.3)$ & $107(4.3)$ & $59(3.7)$ & $24(3.6)$ & $20(2.8)$ & $4(1.9)$ & $17(4.4)$ \\
\hline
\end{tabular}




\begin{tabular}{|c|c|c|c|c|c|c|c|c|}
\hline Characteristic & $\begin{array}{c}\text { Chronic aortic } \\
\text { dissection } \\
(\mathrm{n}=1165) \\
\end{array}$ & $\begin{array}{c}\text { Acute aortic } \\
\text { dissection } \\
(\mathbf{n}=\mathbf{7 0 0})\end{array}$ & $\begin{array}{c}\text { Thoracic aortic } \\
\text { aneurysm } \\
(\mathbf{n}=\mathbf{2 4 6 7}) \\
\end{array}$ & $\begin{array}{l}\text { Thoraco- } \\
\text { abdominal } \\
\text { aneurysm } \\
(n=1587) \\
\end{array}$ & $\begin{array}{c}\text { Thoracic } \\
\text { aortic aneurysm } \\
\text { plus abdominal } \\
\text { aortic aneurysm } \\
\quad(n=665) \\
\end{array}$ & $\begin{array}{c}\text { Rupture of } \\
\text { thoracic aorta } \\
(\mathbf{n}=\mathbf{7 1 0}) \\
\end{array}$ & $\begin{array}{c}\begin{array}{c}\text { Trauma to } \\
\text { thoracic } \\
\text { aorta }(n=216)\end{array} \\
\end{array}$ & $\begin{array}{l}\text { Missing } \\
\text { diagnosis } \\
(\mathbf{n}=\mathbf{3 8 5})\end{array}$ \\
\hline \multicolumn{9}{|l|}{$\begin{array}{r}\text { Prior or concomitant } \\
\text { head/neck bypass }\end{array}$} \\
\hline $\begin{array}{l}\text { Any additional } \\
\text { endoprosthesis\# }\end{array}$ & $382(32.8)$ & $192(27.4)$ & $712(28.9)$ & $714(45.0)$ & $219(32.9)$ & $238(33.5)$ & $40(18.5)$ & 153 (39.7) \\
\hline $\begin{array}{l}\text { Use of TEVAR extension } \\
\text { endoprosthesis }\end{array}$ & $322(27.6)$ & $154(22.0)$ & $649(26.3)$ & $538(33.9)$ & $169(25.4)$ & 203 (28.6) & $32(14.8)$ & $124(32.2)$ \\
\hline $\begin{array}{c}\text { Use of endovascular } \\
\text { aortic repair } \\
\text { endoprosthesis }\end{array}$ & $93(8.0)$ & $49(7.0)$ & $94(3.8)$ & $287(18.1)$ & $61(9.2)$ & $54(7.6)$ & $9(4.2)$ & $69(17.9)$ \\
\hline $\begin{array}{l}\text { Open femoral artery } \\
\text { access for } \\
\text { deployment }\end{array}$ & $807(69.3)$ & 489 (69.9) & $1674(67.9)$ & $1002(63.1)$ & $450(67.7)$ & $487(68.6)$ & $171(79.2)$ & $246(63.9)$ \\
\hline $\begin{array}{l}\text { Open iliac artery access } \\
\text { for deployment }\end{array}$ & $144(12.4)$ & $70(10.0)$ & $407(16.5)$ & $333(21.0)$ & $92(13.8)$ & $110(15.5)$ & $13(6.0)$ & $64(16.6)$ \\
\hline $\begin{array}{c}\text { Nonfemoral, noniliac } \\
\text { artery access*** }\end{array}$ & 251 (21.6) & $163(23.3)$ & $488(19.8)$ & $323(20.4)$ & $147(22.1)$ & $147(20.7)$ & $36(16.7)$ & $96(24.9)$ \\
\hline $\begin{array}{l}\text { Additional use of open } \\
\text { brachial artery access }\end{array}$ & $33(2.8)$ & $20(2.9)$ & $36(1.5)$ & $63(4.0)$ & $8(1.2)$ & $16(2.3)$ & $3(1.4)$ & $13(3.4)$ \\
\hline Cardiac surgery* & $28(2.4)$ & $27(3.9)$ & $60(2.4)$ & $19(1.2)$ & $6(0.9)$ & $8(1.1)$ & $1(0.5)$ & $17(4.4)$ \\
\hline $\begin{array}{l}\text { Use of cardiopulmonary } \\
\text { bypass }\end{array}$ & $31(2.7)$ & $29(4.1)$ & $55(2.2)$ & $25(1.6)$ & $10(1.5)$ & $13(1.8)$ & $3(1.4)$ & $10(2.6)$ \\
\hline Thoracic aortic surgery & $82(7.0)$ & $68(9.7)$ & $141(5.7)$ & $87(5.5)$ & $30(4.5)$ & $59(8.3)$ & $7(3.2)$ & $27(7.0)$ \\
\hline $\begin{array}{l}\text { Abdominal aortic } \\
\text { surgery }\end{array}$ & $45(3.9)$ & $39(5.6)$ & $120(4.9)$ & $178(11.2)$ & $37(5.6)$ & $55(7.8)$ & $0(0.0)$ & $29(7.5)$ \\
\hline $\begin{array}{l}\text { Visceral abdominal aorta } \\
\text { branch surgery }\end{array}$ & $59(5.1)$ & $29(4.1)$ & $120(4.9)$ & $258(16.3)$ & $34(5.3)$ & $46(6.5)$ & $3(1.4)$ & $37(9.6)$ \\
\hline $\begin{array}{c}\text { Head/neck artery } \\
\text { operation } \dagger\end{array}$ & $204(17.5)$ & $94(13.4)$ & $369(15.0)$ & 137 (8.6) & $75(11.3)$ & $70(9.9)$ & $13(6.0)$ & $54(14.0)$ \\
\hline $\begin{array}{l}\text { Upper-extremity artery } \\
\text { operation } \ddagger\end{array}$ & $14(1.2)$ & $13(1.9)$ & $19(0.8)$ & $15(1.0)$ & $5(0.8)$ & $10(1.4)$ & $0(0.0)$ & $5(1.3)$ \\
\hline $\begin{array}{l}\text { Lower-extremity artery } \\
\quad \text { operation } \S\end{array}$ & $168(14.4)$ & $102(14.6)$ & $379(15.4)$ & $247(15.6)$ & $110(16.5)$ & $118(16.6)$ & $20(9.3)$ & $65(16.7)$ \\
\hline \multicolumn{9}{|l|}{ Adjunct procedures } \\
\hline Lumbar drain placement & $225(19.3)$ & $101(14.4)$ & $409(16.6)$ & $390(24.6)$ & $135(20.3)$ & $83(11.7)$ & $5(2.3)$ & $59(15.3)$ \\
\hline
\end{tabular}

Data are presented as $\mathrm{n}(\%)$, mean \pm standard deviation, or median (interquartile range). TEVAR, Thoracic endovascular aortic repair. *Coronary artery bypass grafting/valve/ mechanical circulatory support/transplant. †Subclavian artery/common carotid artery/vertebral artery. $\ddagger$ Axillary/brachial/radial/ulnar artery. $\S$ Profunda/superficial femoral/popliteal/tibial trunk/popliteal artery. ||More than 100 TEVARs in Medicare patients from 2005-2010. $\uparrow$ More than 20 TEVARs in Medicare patients from 2005-2010. \#Use of TEVAR extension endoprosthesis or endovascular aortic repair. **Percutaneous access or antegrade from carotid/proximal aorta.

period associated with TEVAR, $6 \%$ to $12 \%$ of patients died per year, depending on aortic diagnosis. In nonacute aortic dissection and nonaortic trauma patients, this rate was even worse $(9 \%-12 \%)$. The utility of TEVAR in patients without acute disease (acute aortic dissection, trauma, or rupture), who have an annualized death rate of $\geq 10 \%$ per year after the early periprocedural hazard phase of TEVAR, is worth debating.

\section{Comparing Medicare Patients With and Without CPT Codes}

A currently underutilized strength of the Medicare database is the CPT codes provided in the Carrier file. When CPT codes are available, linking them to a patient's hospitalization provides a wealth of data regarding the actual operation performed. CPT codes were available for $66 \%$ of our overall TEVAR cohort.
Comparing patients with and without CPT codes yielded several notable differences. First, patients without CPT codes had a lower prevalence of all documented comorbidities than patients with CPT codes. We do not attribute this finding to a genuine difference in comorbidity but to the greater tendency for patients without CPT codes to have incomplete data in the Medicare database. Our finding that post-TEVAR survival was similar between patients with and without CPT codes seems to support this attribution; if patients without CPT codes actually had fewer comorbidities, we would expect their post-TEVAR survival to exceed that of patients with CPT codes. These findings underscore the risk associated with including patients with and without CPT codes together in an analysis of Medicare patients; that is, comorbidities are likely to be underrepresented in patients without CPT codes. 
TABLE 4. Predictors of survival following thoracic endovascular aortic repair (TEVAR) for subcohort with available Current Procedural Terminology codes $(\mathbf{n}=\mathbf{7 8 9 5})$

\begin{tabular}{|c|c|c|c|c|}
\hline Predictor & $\begin{array}{l}\text { Multivariable hazard ratio } \\
\qquad(\mathbf{9 5} \% \mathrm{CI})\end{array}$ & $P$ value $*$ & $\begin{array}{l}\text { Univariate hazard ratio } \\
\qquad(\mathbf{9 5} \% \mathbf{C I})\end{array}$ & $P$ value $\dagger$ \\
\hline \multicolumn{5}{|l|}{ Demographic characteristic } \\
\hline Age at operation, y & $1.031(1.025-1.036)$ & $<.001$ & $1.032(1.027-1.037)$ & $<.001$ \\
\hline Gender, male & $1.09(1.01-1.18)$ & .04 & $1.05(0.97-1.13)$ & .21 \\
\hline Race, white & & & $0.98(0.89-1.09)$ & .77 \\
\hline Race, African American & $1.03(0.91-1.17)$ & .59 & $1.08(0.96-1.21)$ & .23 \\
\hline Race, Asian & & & $1.02(0.76-1.36)$ & .90 \\
\hline Race, Hispanic & & & $0.80(0.55-1.17)$ & .26 \\
\hline Insurance in addition to Medicare & $0.86(0.66-1.12)$ & .27 & $0.82(0.63-1.07)$ & .14 \\
\hline \multicolumn{5}{|l|}{ Comorbidities } \\
\hline History of myocardial infarction & $1.18(1.03-1.36)$ & .02 & $1.39(1.21-1.59)$ & $<.001$ \\
\hline Ischemic heart disease & & & $1.32(1.19-1.46)$ & $<.001$ \\
\hline Congestive heart failure & $1.19(1.09-1.30)$ & $<.001$ & $1.65(1.52-1.78)$ & $<.001$ \\
\hline Atrial fibrillation & $1.14(1.04-1.25)$ & .005 & $1.44(1.32-1.57)$ & $<.001$ \\
\hline Hyperlipidemia & & & $1.03(0.93-1.13)$ & .61 \\
\hline Hypertension & $0.94(0.78-1.13)$ & .52 & $1.51(1.26-1.80)$ & $<.001$ \\
\hline Chronic obstructive pulmonary disease & $1.26(1.16-1.36)$ & $<.001$ & $1.39(1.29-1.51)$ & $<.001$ \\
\hline Chronic kidney disease & $1.38(1.26-1.50)$ & $<.001$ & $1.77(1.64-1.92)$ & $<.001$ \\
\hline End-stage renal disease & $2.08(1.73-2.42)$ & $<.001$ & $2.47(2.15-2.83)$ & $<.001$ \\
\hline Diabetes & $0.97(0.89-1.06)$ & .54 & $1.15(1.06-1.25)$ & .001 \\
\hline Anemia & $1.22(1.11-1.34)$ & $<.001$ & $1.63(1.50-1.77)$ & $<.001$ \\
\hline Stroke/transient ischemic attack & $1.08(0.98-1.20)$ & .11 & $1.40(1.28-1.53)$ & $<.001$ \\
\hline Alzheimer's/dementia & $1.32(1.17-1.48)$ & $<.001$ & $1.80(1.61-2.02)$ & $<.001$ \\
\hline History of cancer & $1.09(0.98-1.20)$ & .11 & $1.18(1.07-1.30)$ & .001 \\
\hline \multicolumn{5}{|l|}{ Diagnosis } \\
\hline Chronic aortic dissection & & & $0.86(0.76-0.96)$ & .008 \\
\hline Acute aortic dissection & & & $0.96(0.84-1.11)$ & .52 \\
\hline Thoracic aortic aneurysm & $0.85(0.77-0.93)$ & $<.001$ & $0.71(0.65-0.78)$ & $<.001$ \\
\hline Thoracoabdominal aortic aneurysm & & & $1.01(0.92-1.11)$ & .73 \\
\hline $\begin{array}{l}\text { Concomitant thoracic aortic aneurysm and abdominal aortic } \\
\text { aneurysm }\end{array}$ & & & $0.73(0.63-0.85)$ & $<.001$ \\
\hline Rupture & $2.57(2.30-2.87)$ & $<.001$ & $2.80(2.52-3.11)$ & $<.001$ \\
\hline Aortic trauma & & & $0.93(0.72-1.19)$ & .55 \\
\hline Missing thoracic aortic diagnosis & & & $1.41(1.20-1.65)$ & $<.001$ \\
\hline \multicolumn{5}{|l|}{ Previous surgery } \\
\hline Cardiac surgery & & & $1.07(0.95-1.21)$ & .25 \\
\hline Open thoracic aortic & $0.86(0.75-0.98)$ & .002 & $0.92(0.80-1.05)$ & .20 \\
\hline Open abdominal aortic & & & $0.99(0.87-1.13)$ & .86 \\
\hline TEVAR or endovascular aortic repair & $1.26(1.03-1.54)$ & .03 & $1.44(1.18-1.76)$ & $<.001$ \\
\hline Visceral abdominal aorta branch & & & $1.20(1.01-1.43)$ & .04 \\
\hline Head/neck artery $\S$ & & & $0.88(0.77-1.02)$ & .08 \\
\hline Upper-extremity artery $\|$ & & & $1.96(1.14-3.39)$ & .02 \\
\hline Lower-extremity artery $₫$ & & & $1.38(1.12-1.71)$ & .003 \\
\hline \multicolumn{5}{|l|}{ Operative center characteristics } \\
\hline Year of operation & & & $1.01(0.98-1.04)$ & .57 \\
\hline High-volume TEVAR hospital\# & $1.06(0.97-1.15)$ & .22 & $1.13(1.04-1.23)$ & .005 \\
\hline Medium- to high-volume TEVAR hospital** & & & $1.05(0.97-1.14)$ & .22 \\
\hline High-performing TEVAR hospital & $0.53(0.49-0.57)$ & $<.001$ & $0.56(0.51-0.60)$ & $<.001$ \\
\hline \multicolumn{5}{|l|}{ Operation characteristics } \\
\hline TEVAR with subclavian artery coverage & & & $1.15(1.06-1.24)$ & .001 \\
\hline $\begin{array}{l}\text { TEVAR with subclavian artery coverage and prior or concomitant } \\
\text { head/neck bypass }\end{array}$ & & & $1.10(0.98-1.23)$ & .09 \\
\hline TEVAR without subclavian artery coverage & $0.87(0.79-0.95)$ & .002 & $0.88(0.81-0.95)$ & .001 \\
\hline Any additional endoprosthesis $\dagger \dagger$ & & & $1.14(1.05-1.24)$ & .001 \\
\hline
\end{tabular}




\begin{tabular}{|c|c|c|c|c|}
\hline Predictor & $\begin{array}{c}\text { Multivariable hazard ratio } \\
(95 \% \mathrm{CI})\end{array}$ & $P$ value* & $\begin{array}{c}\text { Univariate hazard ratio } \\
\qquad(\mathbf{9 5} \% \mathbf{C I})\end{array}$ & $P$ value \\
\hline Use of TEVAR extension endoprosthesis & & & $1.10(1.01-1.20)$ & .02 \\
\hline Use of endovascular aortic repair endoprosthesis & & & $1.21(1.07-1.38)$ & .003 \\
\hline Open femoral artery access for deployment & & & $0.93(0.86-1.01)$ & .07 \\
\hline Open iliac artery access for deployment & $1.06(0.95-1.18)$ & .28 & $1.12(1.01-1.24)$ & .03 \\
\hline Nonfemoral, noniliac artery access & & & $1.09(0.99-1.19)$ & .09 \\
\hline Open brachial artery access for deployment & & & $1.27(1.00-1.61)$ & .05 \\
\hline Cardiac surgery $\ddagger$ & $1.57(1.22-2.03)$ & .001 & $1.62(1.27-2.05)$ & $<.001$ \\
\hline Use of cardiopulmonary bypass & & & $1.34(1.05-1.73)$ & .02 \\
\hline Thoracic aortic surgery & $1.46(1.25-1.70)$ & $<.001$ & $1.62(1.41-1.86)$ & $<.001$ \\
\hline Abdominal aortic surgery & $1.29(1.12-1.49)$ & .001 & $1.61(1.41-1.85)$ & $<.001$ \\
\hline Visceral abdominal aorta branch surgery & $1.46(1.27-1.68)$ & $<.001$ & $1.63(1.43-1.85)$ & $<.001$ \\
\hline Head/neck artery operation $\S$ & $1.22(1.08-1.38)$ & .001 & $1.25(1.12-1.40)$ & $<.001$ \\
\hline Upper-extremity artery operation $\|$ & & & $1.24(0.89-1.80)$ & .19 \\
\hline Lower-extremity artery operation $\uparrow$ & & & $1.29(1.16-1.42)$ & $<.001$ \\
\hline \multicolumn{5}{|l|}{ Adjunct procedures } \\
\hline Lumbar drain placement & $0.99(0.89-1.10)$ & .88 & $0.93(0.84-1.03)$ & .19 \\
\hline
\end{tabular}

Also significant was the difference in insurance status between patients with and without CPT codes. Nearly $50 \%$ of patients without CPT codes had insurance in addition to Medicare (compared with only $2.6 \%$ of patients with CPT codes), implying that for many patients with additional insurance, CPT codes are not billed directly to Medicare. Analyses of Medicare data must be account for these differences.

\section{Limitations}

Our study was limited by its retrospective design; its susceptibility to selection bias; the variability of ICD-9 and CPT code documentation across hospitals and regions; and the fact that the data from this administrative database are not audited or adjudicated for comorbidities, diagnoses, or procedures performed. We attempted to address these limitations by stratifying patients by whether they had CPT codes, and by using multivariable regression analyses to identify variables that predicted post-TEVAR survival. Nevertheless, unmeasured variables and the observational design of this study leave ample room for residual bias to confound our results. Also, ICD-9 codes do not fully capture the spectrum of thoracic aortic disease, and our aortic disease selection algorithm is imperfect in its ability to stratify patients appropriately. As well, it is possible that interactions exist between aortic disease and other patient variables that we were unable to explore in this analysis. Finally, given the size of the Medicare database, it is impossible to validate data entered into it, and some amount of inaccuracy should be expected, although random misclassification of data would not be expected to alter our findings.

\section{CONCLUSIONS}

TEVAR has been applied to a multitude of aortic diseases in the Medicare population, and early and late post-TEVAR survival varies significantly by disease. Less complex aortic disease is associated with less procedural complexity and improved post-TEVAR survival. Even among those patients who survive 6 months after their initial TEVAR, $6 \%$ to $12 \%$ die per year thereafter, depending on aortic disease. In this era of cost-effective medicine, the high late hazard for death of TEVAR recipients must be considered when one is deciding whether to offer this therapy to patients with nonacute conditions. Age, male gender, patient comorbidities, previous operations on the descending thoracic aorta, aortic disease, operative complexity, and hospital effect all predict post-TEVAR survival. Hospital effect is probably a surrogate for some combination of patient selection, operative competence, and the quality of postoperative clinical care and long-term management. Analyses of outcomes in TEVAR recipients using the Medicare database should adjust for underlying diagnoses and the presence of CPT codes, as well as use CPT codes to appropriately classify patients by procedural details to avoid selection bias. Finally, the post-TEVAR outcomes noted in this study reflect the daily practice of US surgeons, and the survival rates can serve as a real world benchmark for comparison with outcomes associated with newer technologies and therapies.

The authors thank Bruce A. Reitz and Michael D. Dake for funding the acquisition of Medicare data. Justin Schaffer and Bharathi Lingala had full access to all of the data in the study and take responsibility for the integrity of the data and the accuracy of the data analysis. 


\section{References}

1. Dake MD, Miller DC, Semba CP, Mitchell RS, Walker PJ, Liddell RP. Transluminal placement of endovascular stent-grafts for the treatment of descending thoracic aortic aneurysms. N Engl J Med. 1994;331:1729-34.

2. Scali ST, Goodney PP, Walsh DB, Travis LL, Nolan BW, Goodman DC, et al. National trends and regional variation of open and endovascular repair of thoracic and thoracoabdominal aneurysms in contemporary practice. $J$ Vasc Surg. 2011;53:1499-505.

3. Walker KL, Shuster JJ, Martin TD, Hess PJ Jr, Klodell CT, Feezor RJ, et al. Prac tice patterns for thoracic aneurysms in the stent graft era: health care system implications. Ann Thorac Surg. 2010;90:1833-9.

4. Demers P, Miller DC, Mitchell RS, Kee ST, Sze D, Razavi MK, et al. Midterm results of endovascular repair of descending thoracic aortic aneurysms with first-generation stent grafts. J Thorac Cardiovasc Surg. 2004;127:664-73.

5. Shah AA, Barfield ME, Andersen ND, Williams JB, Shah JA, Hanna JM, et al. Results of thoracic endovascular aortic repair 6 years after United States Food and Drug Administration approval. Ann Thorac Surg. 2012;94:1394-9.

6. Dake MD, Kato N, Mitchell RS, Semba CP, Razavi MK, Shimono T, et al. Endovascular stent-graft placement for the treatment of acute aortic dissection. $N$ Engl J Med. 1999;340:1546-52.

7. White RA, Miller DC, Criado FJ, Dake MD, Diethrich EB, Greenberg RK, et al. Report on the results of thoracic endovascular aortic repair for acute, complicated, type B aortic dissection at 30 days and 1 year from a multidisciplinary subcommittee of the Society for Vascular Surgery Outcomes Committee. J Vasc Surg. 2011;53:1082-90.

8. Cambria RP, Crawford RS, Cho JS, Bavaria J, Farber M, Lee WA, et al. A multicenter clinical trial of endovascular stent graft repair of acute catastrophes of the descending thoracic aorta. J Vasc Surg. 2009;50:1255-64. e1-4.

9. Tehrani HY, Peterson BG, Katariya K, Morasch MD, Stevens R, DiLuozzo G, et al. Endovascular repair of thoracic aortic tears. Ann Thorac Surg. 2006;82: 873-7; discussion 7-8.

10. Moainie SL, Neschis DG, Gammie JS, Brown JM, Poston RS, Scalea TM, et al. Endovascular stenting for traumatic aortic injury: an emerging new standard of care. Ann Thorac Surg. 2008;85:1625-9; discussion 9-30.

11. Svensson LG, Kouchoukos NT, Miller DC, Bavaria JE, Coselli JS, Curi MA, et al. Expert consensus document on the treatment of descending thoracic aortic disease using endovascular stent-grafts. Ann Thorac Surg. 2008;85:S1-41.

12. Hiratzka LF, Bakris GL, Beckman JA, Bersin RM, Carr VF, Casey DE Jr, et al. 2010 ACCF/AHA/AATS/ACR/ASA/SCA/SCAI/SIR/STS/SVM guidelines for the diagnosis and management of patients with Thoracic Aortic Disease: a report of the American College of Cardiology Foundation/American Heart Association Task Force on Practice Guidelines, American Association for Thoracic Surgery, American College of Radiology, American Stroke Association, Society of Cardiovascular Anesthesiologists, Society for Cardiovascular Angiography and Interventions, Society of Interventional Radiology, Society of Thoracic Surgeons, and Society for Vascular Medicine. Circulation. 2010;121:e266-369.

13. Nienaber CA, Rousseau H, Eggebrecht H, Kische S, Fattori R, Rehders TC, et al. Randomized comparison of strategies for type B aortic dissection: the INvestigation of STEnt Grafts in Aortic Dissection (INSTEAD) trial. Circulation. 2009; 120:2519-28.

14. Nienaber CA, Kische S, Rousseau H, Eggebrecht H, Rehders TC, Kundt G, et al. Endovascular repair of type B aortic dissection: long-term results of the randomized investigation of stent grafts in aortic dissection trial. Circ Cardiovasc Interv. 2013;6:407-16.

15. Makaroun MS, Dillavou ED, Kee ST, Sicard G, Chaikof E, Bavaria J, et al. Endovascular treatment of thoracic aortic aneurysms: results of the phase II multicenter trial of the GORE TAG thoracic endoprosthesis. J Vasc Surg. 2005;41:1-9.

16. Go MR, Cho JS, Makaroun MS. Mid-term results of a multicenter study of thoracic endovascular aneurysm repair versus open repair. Perspect Vasc Surg Endovasc Ther. 2007;19:124-30.

17. Matsumura JS, Cambria RP, Dake MD, Moore RD, Svensson LG, Snyder S. International controlled clinical trial of thoracic endovascular aneurysm repair with the Zenith TX2 endovascular graft: 1-year results. J Vasc Surg. 2008;47:247-57; discussion 57.

18. Fairman RM, Criado F, Farber M, Kwolek C, Mehta M, White R, et al. Pivotal results of the Medtronic Vascular Talent Thoracic Stent Graft System: the VALOR trial. J Vasc Surg. 2008;48:546-54.

19. Foley PJ, Criado FJ, Farber MA, Kwolek CJ, Mehta M, White RA, et al. Results with the Talent thoracic stent graft in the VALOR trial. J Vasc Surg. 2012;56:1214-21.e1.

20. Fairman RM, Tuchek JM, Lee WA, Kasirajan K, White R, Mehta M, et al. Pivotal results for the Medtronic Valiant Thoracic Stent Graft System in the VALOR II trial. J Vasc Surg. 2012;56:1222-31.e1.
21. Goodney PP, Travis L, Lucas FL, Fillinger MF, Goodman DC, Cronenwett JL, et al. Survival after open versus endovascular thoracic aortic aneurysm repair in an observational study of the Medicare population. Circulation. 2011;124:2661-9.

22. Jones DW, Goodney PP, Nolan BW, Brooke BS, Fillinger MF, Powell RJ, et al. National trends in utilization, mortality, and survival after repair of type B aortic dissection in the Medicare population. J Vasc Surg. 2014;60:11-9.

23. Gorina Y, Kramarow EA. Identifying chronic conditions in Medicare claims data: evaluating the Chronic Condition Data Warehouse algorithm. Health Serv Res. 2011;46:1610-27.

24. Seabrook GR. Current Procedural Terminology (CPT) coding for descending thoracic aorta endovascular repair. J Vasc Surg. 2006;43(Suppl A):106A-10A.

25. Seabrook GR. Current Procedural Terminology (CPT) coding for endovascular intervention in the descending thoracic aorta. J Vasc Surg. 2010;52(Suppl): 103S-6S.

26. Thabut G, Christie JD, Kremers WK, Fournier M, Halpern SD. Survival differences following lung transplantation among US transplant centers. JAMA. 2010;304:53-60.

27. Therneau TM, Grambsch PM, Pankratz VS. Penalized survival models and frailty. J Comput Graph Stat. 2003;12:156-75.

28. Morales DL, McClellan AJ, Jacobs JP. Empowering a database with national long-term data about mortality: the use of national death registries. Cardiol Young. 2008;18(Suppl 2):188-95.

29. Kaplan E, Meier P. Nonparametric Estimation from Incomplete Observations. J Am Stat Assoc. 1958;53:457-81.

30. Bland JM, Altman DG. The logrank test. BMJ. 2004;328:1073.

31. Finkelstein DM, Muzikansky A, Schoenfeld DA. Comparing survival of a sample to that of a standard population. J Natl Cancer Inst. 2003;95:1434-9.

32. Cox DR. Regression Models and Life-Tables. J R Stat Soc Series B Stat Methodol. 1972;34:187-220.

33. Grambsch PM, Therneau TM. Proportional hazards tests and diagnostics based on weighted residuals. Biometrika. 1994;81:515-26.

34. Hosmer DW, Lemeshow S, May S. Applied survival analysis: regression modeling of time-to-event data. 2nd ed. Hoboken: Wiley-Interscience; 2008.

35. Akaike H. A new look at the statistical model identification. IEEE Trans Automat Contr. 1974; 19:716-23.

36. Rothman KJ. No adjustments are needed for multiple comparisons. Epidemiology. 1990;1:43-6.

\section{Discussion}

Dr Justin M. Schaffer (Palo Alto, Calif). Thoracic endovascular aortic repair (TEVAR) is the placement of a manmade conduit across a diseased segment of aorta, usually from a peripheral artery. Before the advent of this therapy the descending thoracic aorta required treatment with a left thoracotomy and necessitated a period of ischemia and/or the use of cardiopulmonary bypass. Many patients with thoracic aorta disease were too sick to sustain these morbid operations, and-necessity being the mother of invention-the stent graft was born. The past 25 years have borne witness to incredible advances in the endovascular treatment of thoracic aorta disease. From 1992 with the first application of TEVAR to a thoracic aortic aneurysm, the therapy has seen its indications expanded to acute aortic catastrophes. The first stent graft received US Food and Drug Administration approval in 2005 and since that time the incidence of TEVAR in the United States has dramatically risen. This expediential growth has been captured by 2 separate analyses, 1 of the nationwide impatient sample, and the other the Medicare database, both showing the significant rise in the instance of TEVAR, particularly, since 2005.

Presently TEVAR is recommended for thoracic aorta aneurysms at least twice the size of the adjacent aorta. It is recommended in acute aortic catastrophes such as acute complicated Stanford type B aortic dissections and traumatic tears of the descending thoracic aorta. However, there are some limitations to the use of TEVAR, as we saw with the INSTEAD trial, the first randomized controlled trial undertaken for the use of TEVAR. This 
study specifically applied TEVAR to uncomplicated chronic Stanford type B aortic dissections and found no reduction in 2- or 5-year all-cause mortality in these patients. Thus, performing TEVAR in a stable chronic Stanford type B aortic dissection is an off-label use of the therapy.

With this background in mind, our study had several objectives. First, we endeavored to appraise the application of TEVAR to thoracic aortic disease in a real world cohort. In particular, we were interested to see the aortic disease breakdown of TEVAR because it has been released into the wild with Food and Drug Administration approval. Second, we were interested in assessing longitudinal post-TEVAR survival, both overall and stratified by aortic diagnosis. Finally, we endeavored to evaluate predictors of post-TEVAR survival. We retrospectively reviewed data for all identifiable Medicare beneficiaries who underwent TEVAR. Survival status, date of death, and date of last known follow-up we evaluated using Medicare-determined death data. These data inform the Social Security Death Master File. Preoperative comorbidities were generated from the chronic conditions warehouse Medicare supplementary file. Aortic diagnosis was ascertained through the use of hospital International Classification of Diseases, Ninth Revision (ICD-9), diagnosis codes and detailed operative characteristics were derived from surgeon-built Current Procedural Terminology (CPT) codes. Longitudinal survival was assessed using the Kaplan Mind method; Cox proportion hazards regression analysis determined predictors of post-TEVAR survival. A mixed-effect model was employed allowing us to model interhospital variability as a random effect. All 1000 hospitals that performed TEVAR on Medicare patients were ranked based on each hospital's independent association with survival, and a variable coding for the one-third of hospitals with the best postTEVAR survival was included in our final regression model.

Our cohort was composed of nearly 12,000 patients. About twothirds of these patients had identifiable CPT codes and one-third did not. From the CPT codes we were able to identify detailed operative characteristics. We used an algorithm that identified ICD-9 codes to determine an aortic diagnosis, and in about $6 \%$ of patients our algorithm was unable to ascertain an aortic diagnosis.

Here we have a breakdown of demographics in Medicare TEVAR recipients. The average age in our cohort was 74 years, $55 \%$ of TEVAR recipients were men, $83 \%$ were white, $12 \%$ black, and $17 \%$ had insurance in addition to Medicare. Interestingly, if you look at the breakdown of Medicare patients by CPT codes, $2 \%$ of Medicare patients who had CPT codes had additional insurance, whereas $44 \%$ of Medicare patients without CPT codes had additional insurance. This makes us suspect that patients with a health maintenance organization plan or other such insurance providers do not send individual CPT billing data to Medicare. As for aortic diagnosis, we saw that $10 \%$ of our cohort had an acute aortic dissection, $14 \%$ had a chronic dissection, one-third of patients had a thoracic aortic aneurysm, 20\% had thoracoabdominal aneurysm, and $10 \%$ had aortic rupture.

As expected, TEVAR recipients had a lot of comorbidities. Six percent of the cohort had experienced a previous myocardial infarction, $40 \%$ had congestive heart failure, $20 \%$ had atrial fibrillation, $85 \%$ had a previous diagnosis of hypertension, $45 \%$ had chronic obstructive pulmonary disease, one-third had chronic kidney disease, $4 \%$ were dialysis-dependent, more than half had anemia,
$10 \%$ had Alzheimer disease or dementia, and $15 \%$ had a previous diagnosis of cancer. If you look at the breakdown of these comorbidities by CPT code, what you see is that patients without CPT codes had significantly fewer comorbidities recorded than Medicare database then those with CPT codes. We suspect that this relates to our prior observation that patients with alternative insurance status are not sending their billing data to Medicare (it instead goes to their insurance provider), and thus these comorbidities are not well captured in the cohort of patients without CPT codes.

We divided the 1000 hospitals at which a TEVAR was performed into a high-, medium-, and low-volume center based roughly on the number of Medicare TEVAR recipients. Cutpoints for hospital volume were based on a separate spline analysis. And as previously described, we created a mixed-effect Cox model using all available covariates to help us rank all 1000 hospitals based on their independent association with post-TEVAR survival. The top one-third of hospitals were selected as being high-performing hospitals, and about $45 \%$ of TEVAR recipients underwent TEVAR at 1 of these high performing hospitals.

Of the 12,000 TEVAR Medicare recipients, about 7800 had CPT codes documented in the Medicare database, and for these patients we were able to describe what operation was performed. Roughly one-third of all TEVAR recipients had coverage of the left subclavian artery, and of these 2500 patients, about half had either a prior or a concomitant head and neck arterial bypass. Meanwhile, two-thirds of all TEVAR recipients did not have their left subclavian artery covered and of those only $4 \%$ had a prior or concomitant head and neck arterial bypass. Two-thirds of TEVAR recipients underwent femoral artery exposure, another $15 \%$ had iliac artery exposure, and $20 \%$ had either percutaneous access or had an antegrade stent graft deployment.

Two percent of TEVAR recipients underwent concomitant cardiac surgery with a valve or coronary artery bypass graft, $2 \%$ required the use of cardiopulmonary bypass, $6 \%$ underwent an open descending thoracic aortic surgery, another $6 \%$ had open abdominal aortic surgery, $7 \%$ required an anastomosis to visceral abdominal aortic branch, $15 \%$ required an operation on the lower extremities, and $13 \%$ required a concomitant head and neck arterial bypass. Finally, almost $20 \%$ of all these TEVAR recipients underwent placement of a lumbar drain.

Next we have the Kaplan estimate of survival for the entire cohort of Medicare beneficiaries who underwent TEVAR. Median survival was 4.8 years with $76 \%$ survival at 1 year and $48 \%$ 5-year survival, respectively. Interestingly, when we broke this down by the presence of CPT codes, we found there was no difference in longitudinal postTEVAR survival in patients with and without CPT codes. This is despite the fact that patients without CPT codes had a much lower incidence of comorbidities recorded in the Medicare database. This finding helps to substantiate our suspicion that patients without CPT codes do not have their billing data submitted to Medicare, and thus any analysis of the Medicare database needs to be conscious of the fact that there is a difference between recorded comorbidities between patients with and without CPT codes.

Demographics were predictably associated with post-TEVAR outcomes: age; aortic diagnosis; and, somewhat interestingly, male gender were all associated with worse post-TEVAR survival. Comorbidities were also associated with worse post-TEVAR survival. All comorbidities analyzed, aside from hypertension and a 
history of cancer predicted post-TEVAR death. With respect to surgeries before the current procedure, a history of open abdominal aortic surgery predicted survival, as did having a prior headneck arterial bypass, whereas a previous TEVAR predicted worse TEVAR outcomes, perhaps reflective of patients who sustained endoleaks and required redo stent grafting.

Year of surgery was not correlated with survival, and interestingly, neither was hospital volume. We've undertaken a number of these large cohort analyses, and this is the first time in any such large cohort analyses where hospital volume was not associated with postprocedure outcomes. Instead, interhospital variability-undergoing TEVAR at a certain subset of hospitalshad a massive protective effect on long-term survival. The hospital at which you received your TEVAR had the third-highest association with postprocedure mortality out of all variables analyzed. Only having a ruptured aorta, and whether you were dialysisdependent, had higher associations with post-TEVAR death. In other words, simply by picking the hospital at which you got your TEVAR, a patient can drop his or her hazard of death by $50 \%$. In this new era of outcomes-driven reimbursement, I suspect that Medicare and other insurance providers - and of course patients-would be interested in which hospitals are associated with a significant post-TEVAR survival advantage.

Procedural characteristics also predicted post-TEVAR outcomes. For example, covering the left subclavian artery was associated with improved outcomes, whereas any concomitant operation such as cardiac surgery, open descending thoracic aortic repair, or abdominal aortic aneurysm repair, were associated with postoperative mortality.

There are a number of limitations to any analysis of the Medicare dataset. First, such analyses necessarily require an observational design, with all inherited risks therein. Second, this is unaudited, nonadjudicated billing data. This dataset was never designed to be used to assess survival or predictors of clinical outcomes. Next, although we tried very hard to create a quality diagnosis algorithm, ICD-9 diagnosis codes for thoracic aortic disease leave much to be desired. Our ability to tell you the chronicity of a dissection is based only on whether a patient was previously admitted to a hospital with the same diagnosis. Furthermore we cannot determine whether a dissection is complicated by end-organ ischemia, and we cannot tell you the Crawford extent of a thoracoabdominal aneurysm. Analyses of that level of detail require a different dataset, or combining Medicare data with a separate dataset.

A few concluding remarks. First, the early and late hazard of death after TEVAR depends on a patient's underlying aortic substrate. Aortic rupture has the highest early incidence of postTEVAR death, whereas an isolated thoracic aortic aneurysm has the lowest. Second, increased operative complexity is associated with worst survival. Third, for the first time in my experience, hospital volume did not correlate with improved postsurgical outcomes; instead, there was a clear interhospital variability in outcomes that was an independent effect with significant prognostic implications. This finding is in opposition to open repairs of the descending thoracic aorta or open thoracoabdominal repairs, wherein hospital volume does predict outcomes.

So what reflects these interhospital differences in post-TEVAR survival? Unfortunately, the Medicare database cannot tell us this. I suspect some amalgam of refined patient selection, improved operative and perioperative care, and good long-term follow-up. Plus, I believe that the technical aspects of TEVAR deployment matter much less than performing TEVAR in the right patients. Uncovering the reasons underlying interhospital differences and fixing them represents the next great challenge for procedurebased medical care. And answering these questions can only be done with a more refined dataset. Although I do not think such a dataset currently exists, linking the STS data perhaps to the Medicare TEVAR database certainly represents the first step.

Dr Robbin Cohen (Los Angeles, Calif). I want to congratulate you and the Stanford group who have certainly been the pioneers of endovascular therapy over the years. You have created a large, retrospective, and sophisticated statistical analysis. My first question purely involves the integrity of the data. The Medicare database is popping up more and more in the literature. Mostly epidemiologic and economic studies. You mentioned that it is nonvalidated. You also mention what you believe to be the indications for endovascular therapy, yet in the Medicare database there is no entrance criteria nor criteria for size. Despite the statistical power of the Medicare database, is it really a good foundation for studies evaluating the results of surgical therapy?

Dr Schaffer. That is an excellent question and an insightful one. I think these analyses represent an important first step. It is not perfect by any means and I have talked about a number of limitations with that dataset. But I contend that most hospitals and surgeons have become adept at recording and submitting CPT codes to get paid for services rendered. Using CPT codes to delineate the operation performed represents 1 of the greatest strengths the Medicare database provides, yet very few studies actually link to these data. Our study demonstrates the feasibility and power of this approach. Next, I think the longitudinal outcome data are probably the most highly validated survival data available. They are validated by the National Death Index and Medicare basically informs the Social Security Death Master File, so those longitudinal outcomes data are highly validated. As well, the survival we see in this Medicare group is analogous to what we see in many of the clinical trials for these devices currently in the literature. Also reassuring is that the comorbidities available in the Medicare database all correlate with outcomes, as one would expect. If you want to get fine operative details (such as the length of aorta covered by the stent graft and what aortic zone was chosen to land the stent) you have to go to institutional datasets. The next great step is to link different institutional datasets with Medicare billing data to combine the strengths of each separate dataset.

Dr Cohen. Let's talk about all-cause mortality. This is basically a mortality study, and in your abstract and article you make some recommendations based on the fact that the mortality after all of these procedures is sobering. And you cover a wide range of diagnoses and procedures, and particularly, say for the trauma situation, you point out that obviously mortality is higher early on with trauma. I wonder whether or not those patients died from other injuries as opposed to reasons related to their endovascular therapy. I have seen some references to the cause of death database in Medicare. Does that really exist, and did you consider analyzing cause of death in your trial?

Dr Schaffer. I have yet to analyze Medicare cause of death data. The full dataset of 11 years' worth of patients undergoing cardiothoracic surgery is on the order of 300 gigabytes of data, which 
requires painstaking validation. We certainly plan to look into cause of death data. Your point is well taken that in other studies the incidence of nonaortic death in patients undergoing TEVAR is quite high, and is perhaps the biggest factor regarding the disappointing midterm outcomes in TEVAR recipients-these patients are very sick and often die of their other comorbidities.

Dr Cohen. Finally - and we for instance see this in California in Sea Corp where volume does not necessarily equate to quality - what is the key to quality in the treatment of aortic disease?

Dr Schaffer. That is the million-dollar question. I can't tell you the answer from the Medicare database. I think the major factor underlying interhospital variability is patient selection. With TEVAR there is a very high incidence of late nonaortic death that we don't observe with other cardiac surgical procedures. This late incidence of death is probably secondary to the significant patient comorbidities found in TEVAR recipients. If an institution focuses only on perioperative mortality and not long-term outcomes, I think TEVAR will be indiscriminately applied to patients who are at high risk for nonaortic death within the next year or 2, and this may not be an appropriate allocation of health care expenditures. Again, this is only my intuition, but I really think that it all comes down to strict guidelines to patient selection when deciding in whom we should implant these devices.

\title{
EDITORIAL COMMENTARY
}

\section{Thoracic endovascular aortic repair: Satisfying early results but still a high midterm attrition rate}

\author{
Thierry Carrel, MD
}

See related article on pages 808-23.

Thoracic endovascular aortic repair (TEVAR) has become an alternative treatment for an increasing number of thoracic aortic pathologies, and the immediate results have been promising. In the opinion of most of our patients, TEVAR allows us to avoid open surgery. The high attrition rate during midterm follow-up reported in the article by Schaffer and colleagues in this issue of the Journal, however, is somewhat alarming and requires in-depth analysis. This is of paramount importance, because with accumulating experience, improving device technology, and better imaging modalities, the indications for TEVAR are now slowly expanding to ascending aortic and aortic arch pathologies.

In this respect, Schaffer and colleagues ${ }^{1}$ must be congratulated for performing a careful analysis in more than 10,000 patients treated by TEVAR for various aortic diseases. As could be expected, they found different outcomes for

\footnotetext{
From the Clinic for Cardiovascular Surgery, University Hospital Bern, Bern, Switzerland.

Disclosures: Author has nothing to disclose with regard to commercial support.

Received for publication Nov 26, 2014; accepted for publication Nov 28, 2014; available ahead of print Jan 13, 2015.

Address for reprints: Thierry Carrel, MD, Department of Cardiovascular Surgery, University Hospital Bern, CH-3010 Bern, Switzerland (E-mail: thierry.carrel@ insel.ch).

J Thorac Cardiovasc Surg 2015;149:823-4

$0022-5223 / \$ 36.00$

Copyright (c) 2015 by The American Association for Thoracic Surgery

http://dx.doi.org/10.1016/j.jtcvs.2014.11.090
}

different pathologies. In this regard, this work has the potential to become an important reference for decision making in the care of patients scheduled for repair of any type of thoracic aortic pathology.

The article provides several interesting pieces of information to the surgical community. ${ }^{1}$ One is that broadening the indications is a classic event when new technologies enter into clinical routine. If, however, one of the most common indication for TEVAR, repair of a descending thoracic aortic aneurysm, is considered, active treatment is justified only when the annual risk of rupture would exceed the perioperative risk of repair by either method (endovascular or surgical). ${ }^{2}$ Conservative treatment with medications leaves the patient exposed to the risk of the disease, but sometimes less is more: Schaffer and colleagues ${ }^{1}$ demonstrate that in acute aortic dissection type $\mathrm{B}$, for instance, midterm and late results after TEVAR are not significantly better that those after conservative treatment, confirming that there is no reason to overtreat the disease.

In the treatment of descending thoracic aneurysms, a previous study $^{3}$ found an impressive 97\% freedom from aneurysm-related death. The 25\% 2-year mortality, however, underscored the fact that successful TEVAR does not guarantee long-term survival.

Numerous studies in the past have reported results in cases in which the indications for TEVAR were broadened. The Investigation of Stent Grafts in Patients with Type B Aortic Dissection trial ${ }^{4}$ (comparing TEVAR with optimal medical management) has been the only randomized controlled trial of TEVAR. This trial demonstrated no 